Review

\title{
Biomedical Applications of Wrinkling Polymers
}

Ryan L Dimmock ${ }^{1}$, Xuyiling Wang ${ }^{1}$, Yibin Fu ${ }^{2}$, Alicia J El Haj ${ }^{3}$, Ying Yang ${ }^{1, *}$

1. School of Pharmacy and Bioengineering, Keele University, Stoke-on-Trent ST4 7QB, UK; E-Mails: r.l.dimmock@keele.ac.uk; w7j68@students.keele.ac.uk; y.yang@keele.ac.uk

2. School of Computing and Mathematics, Keele University, Staffs ST5 5BG, UK; E-Mail: y.fu@keele.ac.uk

3. Healthcare Technology Institute, Institute of Translational Medicine, University of Birmingham B15 2TT, UK; E-Mail: a.elhaj@bham.ac.uk

* Correspondence: Ying Yang; E-Mail: y.yang@keele.ac.uk

Academic Editor: Hossein Hosseinkhani

Special Issue: Development and Applications of Engineering Polymers

Recent Progress in Materials

2020, volume 2, issue 1

doi:10.21926/rpm.2001005
Received: December 09, 2019

Accepted: February 12, 2020

Published: February 28, 2020

\begin{abstract}
Advancements in surface engineering and material fabrication techniques have enabled the creation and replication of naturally occurring surface topographies or the extrapolation of natural patterns to become achievable targets. Polymers are used extensively in the field of biomedical sciences for containment, handling, and as cell culture substrates. It is well established that several polymers exhibit good biocompatibility for cell culture, with properties that include exhibiting minimal to no cytotoxicity and being sufficiently hydrophilic to facilitate cell adhesion. However, when using biologically representative materials, there is always a challenge of achieving tissue representative surface topography and architecture. Wrinkles in human skin represent a considerably common surface topography, resulting from aging and maturity of the tissue. Inspired by this natural topography, the present review article discusses the various techniques for generating wrinkle-like patterns on the polymer surfaces, along with their potential biomedical applications. Wrinkling as material science and as a physical concept has been explored only
\end{abstract}

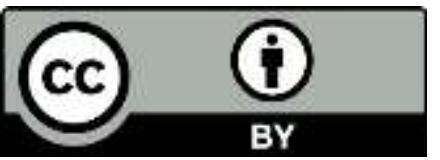

(C) 2020 by the author. This is an open access article distributed under the conditions of the Creative Commons by Attribution License, which permits unrestricted use, distribution, and reproduction in any medium or format, provided the original work is correctly cited. 
during the last century. The transfer of the knowledge related to wrinkling from hard engineering materials to soft elastomers has resulted in the development of an active research field, although it remains in its infancy in terms of application in biomedical science and engineering. It is suggested that wrinkling of polymers, particularly elastomers, would have numerous applications, ranging from tissue modeling in drug and therapy design to in vitro organogenesis for therapeutic explants in the field of regenerative medicine.

\section{Keywords}

Topography; wrinkling; polymer; medical engineering

\section{Introduction}

The use of polymers in an engineering setting has gained momentum during the past century, from niche applications, such as the use of poly (methyl-methacrylate) in aircraft cockpits, to the prevalence of polymers as a dominant material used in everyday life, such as containing our food or as implant materials for medical applications, etc. Table 1 lists the examples of polymers used in research and industry. Bulk properties of the polymer material, including the mechanical properties, cross-linking density, solubility, chemical groups, and hydrophilicity, determine the application of the material. On the other hand, different surface properties of the polymer material, such as roughness, morphology, charge, chemical composition, surface energy, and wettability, influence the interactions of the material with its surrounding environment. Alteration in the surface topography of a material is a cost-effective approach to enhance the required interaction between the material and its surroundings.

It is possible to create synthetic topographies using various engineering methods. These topographies include dots, pillars, grooves, brushes, and etched and molded micro-patterning of a substrate surface. While a great variation may be achieved in patterning, for example in terms of depth, the materials and methodologies used to achieve these topographies have one thing in common, i.e., they are rarely truly biomimetic owing to their high regularity, unnatural form, and immobility, which causes the cells to merely align over or through these substrates. Although such applications have added great value to the understanding of mechanobiology [1] and cell migration [2], both of which have substantial applications in regenerative medicine conceptually, they do not facilitate modeling of a truly biomimetic tissue or a viable tissue engineering method providing transplantable regenerative tissue explants.

Applications of polymers in the generation of microscale and nanoscale topographies are diverse. Wrinkled topography has attracted great attention in the past decade. Wrinkles and similar undulating morphology are widely present throughout the natural world, across various organisms, organ systems, and natural physical structures. Wrinkled topography is found in skin, intestine, plant stem endodermis, upper hyphae of lichens, etc. Wrinkled structures serve multiple purposes, and include exchange surfaces such as the intestinal epithelium and lung alveolar epithelium, barriers such as skin and similar membrane organs, and those providing containment and transport such as vascular tissues. 
Recent Progress in Materials 2020; 2(1), doi:10.21926/rpm.2001005

Table 1 Uses of polymers across different industries and fields of research featuring both historic and current application.

\begin{tabular}{|c|c|c|c|c|c|}
\hline Polymer & Type & Use & Industry / field & Date & Reference \\
\hline $\begin{array}{l}\text { Polyvinylpyrrolidone } \\
\text { (PVP) }\end{array}$ & High $\mathrm{M}_{\mathrm{w}}$ Solid & Isolation through binding low $\mathrm{M}_{\mathrm{w}}$ molecules & Pharmaceutical + Food & 1985 & {$[3]$} \\
\hline $\begin{array}{l}\text { Poly(ethylene oxide) } \\
\text { (PEO) }\end{array}$ & $\begin{array}{l}\text { High } \mathrm{M}_{\mathrm{w}} \\
\text { Solid } \\
\text { Biomaterial }\end{array}$ & Excipient, adhesive, coating, wound dressing, films & $\begin{array}{l}\text { Multi industrial; } \\
\text { pharmaceutical, cosmetic, } \\
\text { construction, fabrication and medical. }\end{array}$ & $\begin{array}{l}2004 \\
2009\end{array}$ & $\begin{array}{l}{[4]} \\
{[5]}\end{array}$ \\
\hline $\begin{array}{l}\text { Polycaprolactone } \\
\text { (PCL) } \\
\text { And its composites }\end{array}$ & $\begin{array}{l}\text { Variable } \mathrm{M}_{\mathrm{w}} \\
\text { Solid } \\
\text { Biomaterial }\end{array}$ & Scaffold production, 3D print-able and electrospun & $\begin{array}{l}\text { Regenerative medicine, tissue } \\
\text { engineering }\end{array}$ & $\begin{array}{l}2018 \\
2019\end{array}$ & $\begin{array}{l}{[6]} \\
{[7]}\end{array}$ \\
\hline $\begin{array}{l}\text { Poly(lactic co-glycolic acid) } \\
\text { (PLGA) }\end{array}$ & $\begin{array}{l}\text { Biomaterial } \\
\text { solid }\end{array}$ & $\begin{array}{l}\text { Cell culture membrane substrate / electrospun } \\
\text { scaffold }\end{array}$ & $\begin{array}{l}\text { Regenerative medicine, tissue } \\
\text { engineering }\end{array}$ & $\begin{array}{l}2018 \\
2019\end{array}$ & $\begin{array}{l}{[8]} \\
{[9]}\end{array}$ \\
\hline $\begin{array}{l}\mathrm{N} \text {-(isobutoxymethyl)- } \\
\text { acrylamide } \\
\text { (NIBAGAT) }\end{array}$ & Polymer Gel & Radio-sensitive dosimeter with tissue equivalence & Medical - radiotherapy & 2019 & {$[10]$} \\
\hline $\begin{array}{l}\text { Poly(ethylene terephthalate) } \\
\text { (PET) } \\
\text { Poly(ethylene } \\
\text { terephthalate)glycol } \\
\text { (PETG) }\end{array}$ & $\begin{array}{l}\text { Solid } \\
\text { Biodegradable } \\
\text { Biocomaptible }\end{array}$ & $\begin{array}{l}\text { PET: strain crystalisation for production of general / } \\
\text { disposable plastic consumables and containers } \\
\text { applications } \\
\text { PETG: thermoformation of clear panels } \\
\text { Both have been used in cell culture applications }\end{array}$ & $\begin{array}{l}\text { Global general use plastics, } \\
\text { commercial, manufacturing, tissue } \\
\text { engineering and } \\
\text { Cell Biology }\end{array}$ & $\begin{array}{l}1996 \\
1999 \\
2014\end{array}$ & $\begin{array}{l}{[11]} \\
{[12]} \\
{[13]}\end{array}$ \\
\hline $\begin{array}{l}\text { Polydimethylsiloxane } \\
\text { (PDMS) }\end{array}$ & $\begin{array}{l}\text { Elastic silicon } \\
\text { rubber solid } \\
\text { Biomaterial }\end{array}$ & $\begin{array}{l}\text { Modelling weather resistant electrical insulation for } \\
\text { outdoor applications } \\
\text { Hydrophobic Sealant } \\
\text { Elastic substrate for the generation of micro/nano } \\
\text { topographies in cell culture }\end{array}$ & $\begin{array}{l}\text { Cell biology, regenerative medicine, } \\
\text { medical devices, power sector and } \\
\text { manufacturing }\end{array}$ & $\begin{array}{l}2005 \\
2011 \\
2019\end{array}$ & $\begin{array}{l}{[14]} \\
{[15]} \\
{[16]}\end{array}$ \\
\hline $\begin{array}{l}\text { Poly(glycerol sebacate) } \\
\text { (PGS) }\end{array}$ & Elastic Solid & Elastic scaffold for bone regeneration & $\begin{array}{l}\text { Regenerative medicine, tissue } \\
\text { engineering }\end{array}$ & 2013 & {$[17]$} \\
\hline $\begin{array}{l}\text { Polypyrrole } \\
\text { (PP) }\end{array}$ & Elastic coating & Wrinkle generation for cell studies & $\begin{array}{l}\text { Tissue engineering } \\
\text { Substrate synthesis }\end{array}$ & 2015 & {$[18]$} \\
\hline
\end{tabular}


Wrinkles are included within the purview of engineered topographies. Engineered topographies have the greatest capacity for structural spontaneity, as evidenced by the production of "bioinspired" wrinkled poly (terafluoroethylene) (PTFE) membranes [19], implying that it is possible to engineer the naturally representative structures. In addition, wrinkles are a continuous waveform structure, and therefore, have a tunable quality. It is possible to completely alter a surface through wrinkling in a manner that would model certain biological conditions and the alterations thereof, such as the application of cosmetic products and treatments.

Wrinkling of a material is a physical phenomenon, while the undulation of a surface is a result of the compression of a surface and the bulk which have distinctly different Young's moduli. The requirement for undulation is that the surface must be far stiffer than the bulk in order to facilitate the sinusoidal buckling of the surface into the substrate, as outlined in a study conducted with stiff polymer films adhered to elastomeric polymer bulks [20]. The bulk should be sufficiently soft so that it allows the deformation arising from the undulating upper layer without flattening into a bulge. There are multiple characterizations of wrinkles available in different contexts, ranging from the mechanical determination of the impact of age on the wrinkling of skin [21] to the physical deformation of materials in engineering applications such as space telescope designing [22]. The requirements for wrinkling stated earlier in the present report are a commonality among these different contexts and applications of this phenomenon, and may, therefore, be exploited to create a tunable topography for both engineering and biomedical applications; an example of such an application is the generation of wrinkles in cured hydrogel scaffolds which are tunable under fine control [23]. The generation of wrinkled polymer surfaces has already been reviewed extensively, with the appreciation of the causation of wrinkling such as material instability and the comparison of the different methods of achieving this phenomenon [24]. Furthermore, control of wrinkling patterns and the comparison of these methods through changes in materials and generation conditions have also been reviewed in relation to applications in metrology [25]. On the basis of these reviews, it may be stated that the material aspects of this field have been established substantially, providing a suitable basis for the subsequent application of this phenomenon in the biomedical fields.

The use of wrinkles in a biomedical application does not just involve achieving a wrinkled substrate and applying cells on the top of it. In order to maintain relevance, the wrinkled topography must be biomimetic in its morphology and the material used must be biocompatible. This inherently presents certain challenges to the traditionally easily wrinkled applications, such as the application of fine metal films to elastomers [26], which is simply unsuitable for the majority of the cell cultures, particularly for stem cells and human cell cultures in which material biocompatibilities must be considered meticulously. The context of biomimetic wrinkles refers to the morphology and the magnitude of the wrinkles, and the wrinkles for each type of cell culture must be representative of the tissue that is being modeled; for example, the amplitude of undulation for an intestinal crypt would be greater than that of a stem cell niche in the upper respiratory tract $[27,28]$. In terms of biocompatibility, the material must be functionalized in a manner that facilitates cell adherence, prevents cytotoxicity, and does not interfere with cell signaling. In tissue engineering, such materials may be specific for each cell because different cell types have different culture requirements, ranging from media composition to the substrate used. This is evidenced by the demonstration of material-guided differentiation in a previous study, in which modification of the substrate resulted in influencing the osteogenic differentiation of 
mesenchymal cells [29]. In this context, patterning of polymers and their biocompatibility has already been reviewed, and it is appreciated that micro-patterning and nano-patterning increase the biocompatibility of polymers through the replication of the extracellular matrix. Multiple polymer preparations, including wrinkled polydimethylsiloxane (PDMS), have been compared previously, and it was concluded that the choice of material and substrate topography determines the extent of biomimetic behavior in an in vitro system, which is vital to the development of advanced biomedical applications [30].

\section{A Brief History of Wrinkling}

Wrinkling as a material science and as a physical concept has been explored only during the last century. The origins of this field are believed to be in the early development of aerospace technologies, with the earliest publications originating from the military research reports concerning the examination of the failure points in the military airplanes in the 1930s [31]. It was within this period that a linear model for the prediction and characterization of the material bulk during the process of wrinkling was proposed [32]. However, it was not until much later (1969) that a derivation of this work leads to the development of a predictive model that was able to predict the wrinkle wavelength from Young's moduli of the film and the substrate [33]. This research formed the basis for the analysis and the development of the understanding of the mechanics underlying sheet metal buckling in manufacturing, particularly in the context of aircraft parts manufacturing. In addition, this research began illustrating relationships among elasticity, stress-strain behaviors, and their subsequent failure patterns, including wrinkling, formulating them together into what was referred to as the "elastic theory" [34]. Downstream of these research applications which were derived exclusively from industry, further research was conducted regarding the phenomenon of wrinkling, particularly on the characterization of the presentation of deformations and their correlation to waveform patterns. Consequently, the dimensions of the substrates being used began evolving, and the utilization of membranes commenced. An example of such a study is the one that involved the determination of the kinematics of non-linear wrinkles in order to quantify the extent of wrinkling in a membrane [35]. Later, further sophisticated models were generated for composite materials, which incorporated thermal and elastic constant predictions [36] and computation of the modified adapted Dynamic Relaxation method to resolve the non-linear problems in regard to the bending and wrinkling of circular plates, marking the introduction of in silico modeling in material engineering in the context of wrinkling [37]. This evolution in the investigation and characterization led to the recent applications, in which wrinkled materials were implemented rather than being investigated. Until the late 1990s, linear models proposed by Biot and Allen had been accepted as the accurate representations of wrinkling behavior. However, using the neo-Hookean model, it was determined that the non-linear model was more accurate [38]. Later research work using the Gent model further demonstrated the transformation of this non-linear model to be more representative of the wrinkled-bilayer system, with the consideration of pre-straining of the film [39]. Examples of the recent applications of wrinkled polymers (discussed later in the report) include smart components in solar energy harvesting [40], alignment of semiconductor nanowires for nanoscale electronics [41], and currently, biomedical applications. 


\section{Techniques for Generating Wrinkles on Polymer Surfaces}

Over the past few decades, researchers have demonstrated that wrinkles may be formed through a two-layer system, where a layer of "hard" skin tightly sits above an elastic substrate layer such as PDMS. If the volume of the bulk changes, either internally or externally, the hard skin would be deformed in order to release this compressive stress, forming wrinkles. The specific methods to form such wrinkles are as follows: (1) Depositing a thin metal film on the top of a heated elastic substrate such as PDMS, followed by cooling the whole system [23], (2) Plasmaoxidizing the top of heated PDMS, followed by cooling [42], and (3) Exposing stretched PDMS to ultraviolet/ozone (UVO), and subsequently releasing it [43, 44]. If the two-layer system is homogenous and no extra forces or patterns exist, the compressive stress in the skin would be distributed isotropically and the wrinkles would form disordered "zig-zag" patterns (Figure 1) [2].

When the disordered wrinkles are zoomed-in, locally ordered wrinkles with specific wavelengths and amplitudes may be observed. The creation of 3D topographies, such as stages and posts, allows the wrinkles to be ordered, as discussed ahead in the report. It was discovered that the wrinkling pattern formed is memorable, and therefore, may reform if the compressive stress is released and created again [45]. In addition to wrinkles, defects and cracks may be formed when the pre-stretched bulk is released, although this effect may be reduced by controlling the releasing rate [43]. The section ahead describes the robust ways of generating wrinkled topography. The majority of these methods generate static wrinkling. However, they do possess the potential to produce dynamically tunable properties.

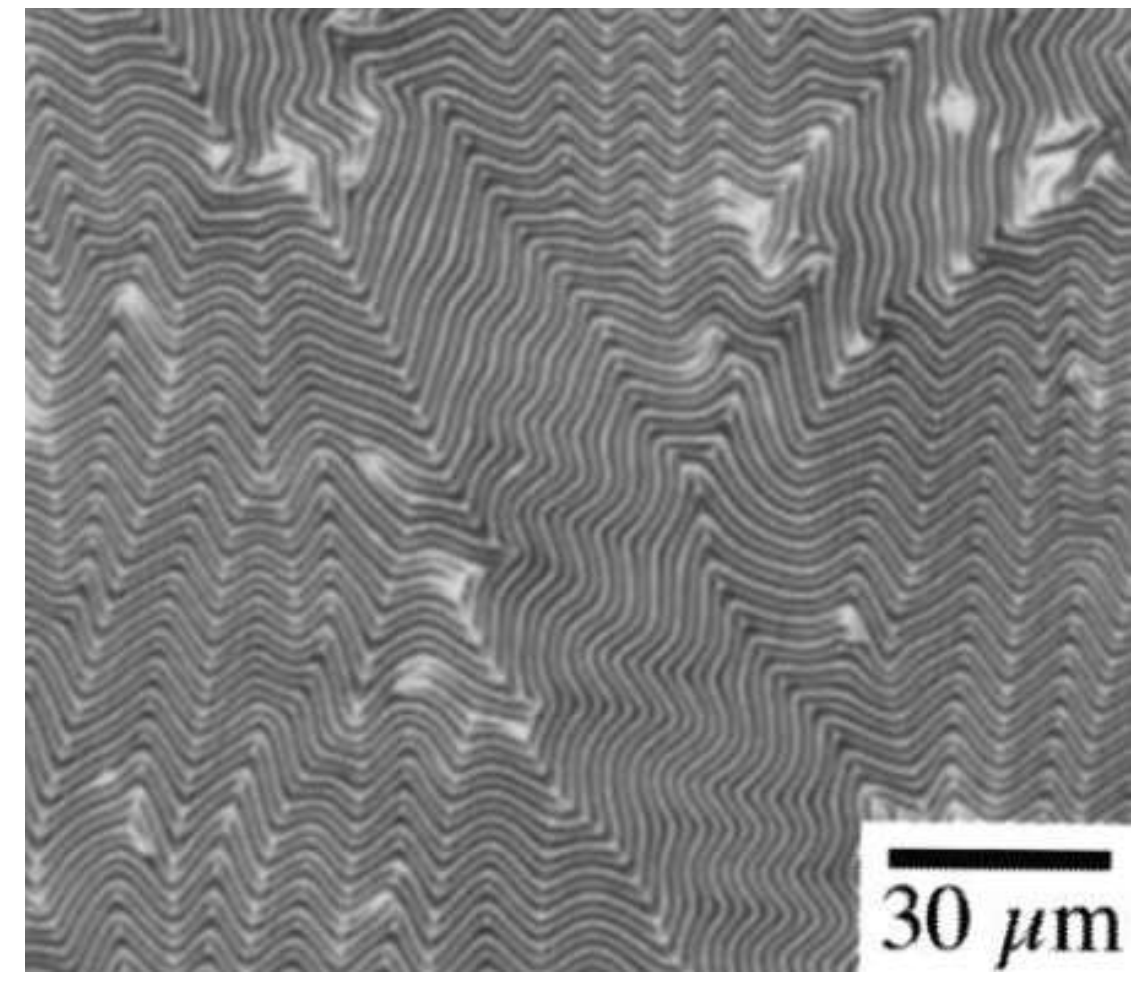

Figure 1 The "zig-zag" wrinkle pattern formed when the compressive stress in the skin is isotropically distributed. Reproduced from an earlier report [42] with the permission of AIP Publishing. 


\subsection{Oxidative Plasma}

Wrinkle generation using oxidative plasma treatment follows an established protocol, which involves pre-stretching the substrate prior to the treatment, followed by relaxation to generate wrinkles $[46,47]$. This method generates a pseudo-dynamic wrinkle topography in which the periodicity of the wrinkles is tunable from the generation of wrinkles in the "relaxed state" of substrate straining to the wrinkles flattening upon the substrate stretching to the treatment strain. Oxidative plasma enables the achievement of the desired modulus differential through the formation of additional covalent cross-linking throughout the upper surface by the addition of $\mathrm{O}^{-}$ to form siloxyl groups with the excited-state oxygen species of the plasma $[48,49]$. This increased oxygen-mediated cross-linking increases the surface stiffness. The oxidative plasma method, which clearly relies on the excited oxygen atoms, cannot penetrate deep into the substrate, with a reported maximum oxidized upper layer thickness of $131 \mathrm{~nm}$ [46], and therefore, provides a distinct boundary for the modulus difference to create the wrinkles.

\subsection{Visible Light Irradiation}

Visible light irradiation utilizes a patterning mechanism inherently inverse to UV treatment as for the materials concerned, visible light is sufficient to induce a reduction in the stiffness, causing a relaxation in the wrinkle waveform, i.e., increasing the wavelength. In this method, a laser is employed to deploy collimated light, ensuring an even treatment across the surface area being targeted. This approach may be used to create a high-fidelity hierarchical wrinkled structure with a high degree of order of wrinkles [50,51].

\subsection{Thermal Wrinkling}

Thermal wrinkling is based on the principle of an increase in the length of metal with the application of heat. This principle applies, prior to being cooled, to an elastomeric substrate, which yields to a certain degree in the direction of contraction when cooled. Following the general principle, the strain and the associated forces are applied upon both stiff metal surface film and elastic bulk [52]. Alternatively, it is possible to achieve the reverse of this process; as demonstrated with the impregnation of gold nanoparticles into polystyrene, it is possible to achieve wrinkling through an increase in temperature [53]. The advantage of this process over the other ones concerned is that it provides a potentially "contactless" method for substrate wrinkling modulation, as this method may be applied through the use of technology such as laser pulses to heat up the metal films post adhesion, followed by cooling to stretch or relax the system, depending on the surface on which the treatment is being applied [54].

\subsection{Wet Surface Chemistry}

Aside from the "dry methods", there are a small number of wet methods (which are uncommon) to achieve wrinkling in polymers. Wet-surface chemical treatment refers to the chemical mediated oxidation of the uppermost surface of a material, leading to its wrinkling. An example of the application of this method is the wrinkling of PDMS microspheres achieved using acid-mediated oxidation. The method was able to achieve labyrinth-like wrinkles over the entire 
surface of the microspheres. It is proposed that microscale substrates may have exciting potential in tumor modeling, organoid production, and micro-carrier (both genetic and drug) applications, where 3-D engineering is required in a fluid environment. However, the microsphere method is not directly translatable to flat and macro-undulating surfaces, and further demonstration is required to determine the reliability of this method in terms of wrinkle generation in culture substrates [55].

\subsection{Gel Swelling}

Another "wet method" for achieving the wrinkling of the surface of polymers is the use of the swelling technique. This technique, in relevance to cell culture, is primarily applied to polymer gels coated with a stiff upper membrane. A solvent is used to increase the volume of the bulk, while the upper membrane remains constrained, which creates the required strain across the surface/bulk modulus differential. An example of the application of this method was the establishment of wrinkle topography through the seeding of the cells themselves upon the gel; the swelling of the gel served as a tuning mechanism that modulated the magnitude of the wrinkles formed [23]. Another previous study that utilized gel swelling involved the application of a polypyrrole coating on swollen PDMS, which was subsequently de-swollen to form a biaxial wrinkled pattern [56]. Owing to the stiffness of the bulk (due to 1:10 PDMS), the strain forces applied to the surface were better considered a biaxial stretch to compression upon de-swelling. This method, when compared to hydrogel swelling, results in a difference in the force distribution, presenting a 3-Dimensional direction of distention upon swelling with the solvent.

\subsection{Coatings}

Several studies have employed coatings in order to generate a definitive difference in material stiffness between the surface and the bulk. The examples include the use of a thin film coating of gold on PDMS and a thin graphene layer on PDMS [26]. The benefit of using coatings is that it is relatively simple to achieve a homogenous thin layer of the order of nanometers using methods such as sputtering and the other similar deposition methods. The examples include the sputter coating of gold over liquid crystal polymer films [18] and the sputter coating of silver and gold on poly-L-lactic acid [57]; in both these examples, the system was subjected to deformations to achieve a wrinkled substrate (the former achieved with photo-isomerization and the latter with thermal stress). The sputtering methods also facilitate the ability to scale up the manufacture processes, as similar procedures are already performed on a large scale in industries such as the automotive industry [58]. However, despite their biocompatibility, the use of metals and graphene in cell culture for the generation of wrinkles raises challenges in the study of cell migration, since metals do not facilitate the biomimetic cell adhesion without substantial additional coating. The use of biocompatible polymeric coatings generally requires using adhesives (because of which this method could be considered a "semi-wet" treatment method) or thermal sintering for achieving adhesion, which in long-term cell cultures proves to be difficult to handle and to achieve sufficient difference in surface to bulk moduli (owing to the formation of a modulus gradient), rendering this approach much less favorable compared to the other approaches. 


\section{Elastomers in Wrinkling: The Materials of Choice}

As stated earlier, polydimethylsiloxane, PDMS is an elastomeric polymer with the chemical structure of $\left(\mathrm{HO}-\left[-\mathrm{Si}\left(\mathrm{CH}_{3}\right)_{2}-\mathrm{O}\right]-\mathrm{H}\right)_{n}$ which may be further cross-linked through oxidative cross-linking between the silicon and oxygen atoms present in neighboring polymer fibers [49, 59]. PDMS possesses a multitude of desirable and also tunable properties which may be attained both during the production of this polymer and during the treatment of the polymer post-production. Among these properties; variable hydrophobicity, total biocompatibility in cell culture, and variable stiffness $[60,61]$ are of particular interest in the designing of cell culture systems, as they enable the generation of biomimetic topographies which are representative of the target tissue across various tissue types, particularly the soft tissues and the surface (both epithelial and endothelial) tissues. The examples of tissue replication using defined substrate topography and elastomers include the layered parylene/PDMS approach to intestine replication [62], smooth muscle micropatterning of versaflex thermoplastic elastomer for smooth muscle culture which also has potential vascular applications [63], and electrospun elastic composite scaffolds for cardiac patch creation [64]. Although different tissues have different functions, such as the absorptive function of the intestine, the barrier function of the skin, the semi-permeable nature of the vasculature, or the contractile function of myocardium, they all require a certain degree of elasticity in order to function and exist without sustaining an injury. Therefore, in designing a truly biologically representative culture system, an elastic substrate is the fundamental necessity, as surface elasticity is required to properly activate the adhesion proteins and naturally stimulate the cytoskeleton [65].

It is these functional qualities, alongside the practical considerations, that enable a simple elastomer such as PDMS to be an attractive candidate for the choice of substrate and scaffold production material in tissue culture applications. PDMS has a widely variable modulus that varies on the basis of the ratio of curing agent to elastomer mix (Table 2) and is simple to prepare using a well-established protocol. In comparison to other more complex elastomers (Table 3), PDMS has its clear advantages, although it should not be neglected that these preparations have their niche purposes, particularly in terms of their functionalization which is specific to their target cell/tissue type. An example of this would be the POSS/PCL/graphene conductive nanocomposite, which exhibits neural-specific biocompatibility and may be employed in neural tissue engineering and neurosurgical applications [66]. In its pristine state, PDMS is hydrophobic, inherently presenting a significant obstacle for cell culture [67]. However, a plethora of "treatments" are available which when applied to PDMS, enable achieving better hydrophilicity, and consequently, better cell adhesion; examples of such treatments include protein adhesion [68], plasma oxidation [67], ultraviolet light-mediated oxidation [69], and thin-film depositions [70]. Furthermore, a few of these treatments may be exploited to achieve, in addition to just better biocompatibility for cell culture, the generation of the required topography for the cell culture, wrinkles in particular. 
Table 2 Properties of biocompatible polymers utilised biological applications.

\begin{tabular}{|c|c|c|c|c|}
\hline Material & Tensile Strength & Youngs' Modulus & $\begin{array}{l}\text { Hydrophobicity relative to } \\
\text { cell attachment }\end{array}$ & Reference \\
\hline $\begin{array}{l}\text { Poly(urethane)urea - polyhedral oligomeric } \\
\text { silsequioxane nanohybrid }\end{array}$ & Not reported & $0.80-0.1 \mathrm{MPa}$ & $\begin{array}{l}\text { Hydrophobic, requires pre- } \\
\text { incubation with medium }\end{array}$ & [71] \\
\hline $\begin{array}{l}\text { Polyurethane co-polymerised with varying } \\
\text { ratios thereof with; poly( } \varepsilon \text {-caprolactone) } \\
\text { and } 4,4 \text { '-diphenylmethane diisocyanate. } \\
\text { Extended further with varying ratios } \\
\text { thereof with; chitin, } 1,4 \text { butane diol } \\
\text { Polyurethane }\end{array}$ & $5.1-11.6 \mathrm{MPa}$ & $\begin{array}{l}\text { Not reported } \\
5-63.6 \mathrm{MPa}\end{array}$ & $\begin{array}{l}\text { Hydrophilic } \\
\text { Hydrophobic }\end{array}$ & $\begin{array}{l}{[72]} \\
{[73]}\end{array}$ \\
\hline Poly(1,8-octanediol-co-citric acid) & $\begin{array}{l}2.93 \pm 0.09-11.15 \pm 2.62 \\
\mathrm{MPa}\end{array}$ & $\begin{array}{l}1.6 \pm 0.05-13.98 \pm 3.05 \\
\mathrm{MPa}\end{array}$ & Hydrophilic & [15] \\
\hline $\begin{array}{l}\text { Poly(methylhydrosiloxane), modified with } \\
\text { 4-Methoxyphenyl 4-(2-butenyloxy)benzoate } \\
\text { and 1,4-di(10-undecenyloxy)benzene }\end{array}$ & \multicolumn{2}{|l|}{ Not reported } & $\begin{array}{l}\text { Hydrophobic, required } \\
\text { heating with culture media }\end{array}$ & [73] \\
\hline Poly(ester urethane)urea & $8.5 \pm 1.8 \mathrm{MPa}$ & $2.8 \pm 1.1 \mathrm{MPa}$ & Hydrophilic & [74] \\
\hline $\begin{array}{l}\text { Polydimethylsiloxane } \\
\text { Stiffness variants; } \\
\text { (Elastomer to curing agent) }\end{array}$ & Not reported & $\begin{array}{l}2.1 \pm 0.1 \mathrm{MPa}(10: 1) \\
1.02 \pm 0.1 \mathrm{MPa}(20: 1) \\
240 \pm 19 \mathrm{Kpa}(40: 1)\end{array}$ & $\begin{array}{l}\text { Hydrophobic, can be treated } \\
\text { in a variety of methods to } \\
\text { facilitate cell attachment }\end{array}$ & {$[60]$} \\
\hline $\begin{array}{l}\text { Poly(caprolactone-diol citrate)/Chitin } \\
\text { nanocrystal composite }\end{array}$ & Not reported & $\begin{array}{l}0.81 \pm 0.1-43.24 \pm 2.54 \\
\text { MPa with increased } \\
\text { Chitin nanocrystal } \\
\text { incorporation }\end{array}$ & Hydrophilic & {$[75]$} \\
\hline PLGA & $27.5 \pm 4.8 \mathrm{MPa}$ & $629.3 \pm 77.4 \mathrm{MPa}$ & - & $\begin{array}{l}{[76]} \\
{[77]}\end{array}$ \\
\hline PET & Not reported & $1-3 \mathrm{GPa}$ & - & $\begin{array}{l}{[78]} \\
{[79]}\end{array}$ \\
\hline
\end{tabular}


Table 3 Summary of current studies using Elastomeric polymers within the scope of regenerative medicine.

\begin{tabular}{|c|c|c|c|}
\hline Application & Polymer(s) & Date & Reference \\
\hline $\begin{array}{l}\text { Films for the replication of urethra epithelium in } \\
\text { modelling integrin binding }\end{array}$ & $\begin{array}{l}\text { Poly-(R)-3-hydroxybutyrate and Poly-(L)-lactic acid with incorporation of } \\
\text { Hyaluronan, Amylose and Collagen }\end{array}$ & 2019 & {$[80]$} \\
\hline $\begin{array}{l}\text { Conductive polymers in creating cell scaffolds for 3D } \\
\text { culture with electrochemical sensing }\end{array}$ & $\begin{array}{l}\text { Polydimethylsiloxane coated with poly(3,4,ethylenedioxythiophene) modified } \\
\text { with platinum nanoparticles }\end{array}$ & 2019 & [81] \\
\hline Cardiac tissue chips for disease modelling & Polydimethylsiloxane in agarose mould with fibrin encapsulated cells & 2019 & [82] \\
\hline Liquid crystal elastomer for dynamic cell culture & $\begin{array}{l}\text { Poly(methylhydrosiloxane), modified with 4-Methoxyphenyl 4-(2- } \\
\text { butenyloxy)benzoate and 1,4-di(10-undecenyloxy)benzene }\end{array}$ & 2014 & [83] \\
\hline $\begin{array}{l}\text { Porous scaffolds in biocompatibility analysis of novel } \\
\text { elastomer preparation }\end{array}$ & Poly(1,8-octanediol-co-citric acid) & $\begin{array}{l}2004 \\
2004\end{array}$ & $\begin{array}{l}{[84]} \\
{[73]}\end{array}$ \\
\hline $\begin{array}{l}\text { Novel film preparation for fibroblast cell culture - } \\
\text { biocompatibility study }\end{array}$ & $\begin{array}{l}\text { Polyurethane co-polymerised with varying ratios thereof with; poly }(\varepsilon- \\
\text { caprylactone) and } 4,4^{\prime} \text {-diphenylmethane diisocyanate. Extended further with } \\
\text { varying ratios thereof with; chitin, } 1,4 \text { butane diol }\end{array}$ & 2009 & {$[72]$} \\
\hline $\begin{array}{l}\text { Electrosprayed smooth muscle cells with electrospun } \\
\text { PEUU fibres for elastic tissue replication }\end{array}$ & Poly(ester urethane)urea (PEUU) & 2006 & {$[85]$} \\
\hline $\begin{array}{l}\text { Biodegradable elastomer composite for cell scaffold } \\
\text { engineering }\end{array}$ & Poly(caprolactone-diol citrate) chitin nano crystal composite & 2019 & [75] \\
\hline $\begin{array}{l}\text { Scaffold fabrication for chondrogenic and osteogenic } \\
\text { differentiation of human mesenchymal stem cells }\end{array}$ & $\begin{array}{l}\text { Poly(urethane)urea - polyhedral oligomeric silsequioxane nanohybrid } \\
\text { (PUU/POSS) }\end{array}$ & 2018 & [71] \\
\hline $\begin{array}{l}\text { Casting of decellularized intestine tissue to replicate } \\
\text { intestinal crypt morphology }\end{array}$ & Layered Parylene and PDMS & 2016 & {$[62]$} \\
\hline Electrospun Elastic cardiac patch creation & $\begin{array}{l}\text { Poly(1,8-octanediol-cocitrate) and Poly(I-lactic-acid-co-caprolactone) } \\
\text { composite }\end{array}$ & 2012 & [64] \\
\hline $\begin{array}{l}\text { Electrically conductive, neural specific, material for } \\
\text { neuronal tissue engineering / neurosurgery }\end{array}$ & $\begin{array}{l}\text { Polyhedral oligomeric silsequioxane polycaprolactone copolymer and } \\
\text { graphene nanocomposite (POSS/PCL/Graphene) }\end{array}$ & 2019 & {$[66]$} \\
\hline
\end{tabular}




\section{Patterning the Wrinkles}

Optimizing the wrinkled topography is the first step. However, for practical applications, obtaining the required morphology of the wrinkles is the next necessary consideration. A common technique for the induction of desired topographies is patterning. Various wrinkling patterns have been generated by changing the compressive stress in various directions through the film. This change in the compressive stress in different directions may be brought about by using embedded stages/posts or through the application of external force $[24,42,86]$. Variable wrinkle patterns may be achieved through the use of discrete alternating regions with varied modulus within a film, resulting in separate regions having different wrinkling patterns on the same film. Alternatively, gradient approaches to vary the modulus of the film may be used to modify the wavelength of the generated wrinkles continuously $[86,87]$. Figure 2 depicts the manifestations of both of these approaches.
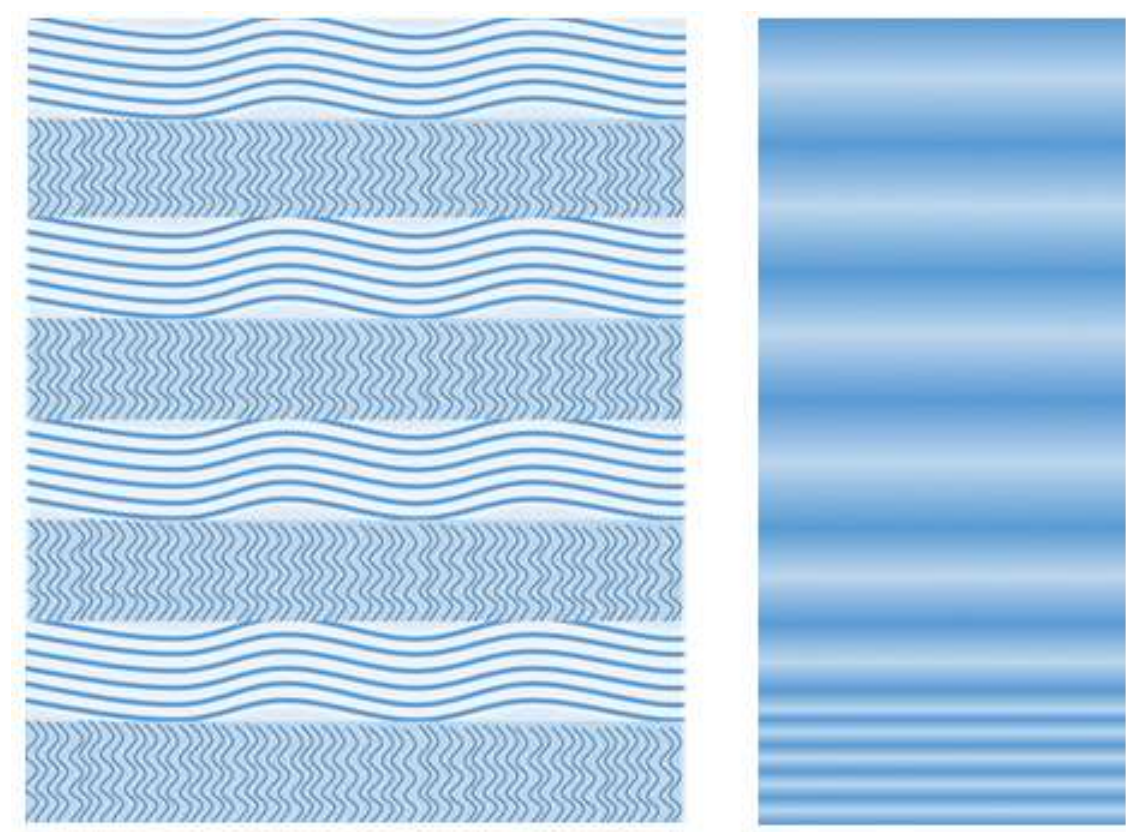

Figure 2 Illustrations of gradient controlled wrinkling patterns. Left, alternating regions of elastomeric skin at different moduli manifested in different wrinkling patterns propagating in different directions [68]. Right, using a gradient of surface modulus to continuously change the wavelength of uniaxial wrinkles formed [69].

The wrinkle patterns may generally be explained by creating "relief" structures that are able to decrease the compressive stress of the skin in a certain direction. The wrinkling direction is always in parallel to the direction with larger compressive stress. For instance, if stages are created along the $x$-axis, the compressive stress along the $y$-axis rather than the $x$-axis would be reduced because of being disconnected in the skin. Therefore, the compressive stress would be larger in the lateral direction than that vertically, leading to the propagation of wrinkle waveforms perpendicular to the created stages [24]. Furthermore, it was discovered that when circular depression is created, wrinkles would form herringbone patterns [52]. The whole pattern may be explained by achieving the lowest elastic energy. Recently, further sophisticated methods have been developed to tune and even erase the wrinkles using photo-isomerization [50] or by combining light irradiation with a 
multi-layered system to modify the wrinkles [51]. However, all the patterning methods may be explained by a change in the compressive force in a certain direction in order to direct the wrinkles. Since light irradiation allows strict control, rapid application, and possible modulation of the wrinkles prior to and after treatment, the future techniques for modulating wrinkles may rely more on light irradiation to modify the molecular structures of the different layers, rather than on using heat or surface stages/posts which are time-consuming and expensive.

It is possible to generate various types of wrinkling patterns using patterning with increasing complexity. Uniaxial wrinkles refer to the wrinkling pattern generated from a uniaxial strain. Current methods use uniaxially pre-strained PDMS with a surface modification such as a thin coating of gold applied on the surface, which is subsequently relaxed, as depicted in Figure 3A [88]. The wrinkles are generated along the direction of propagation of the waveform, parallel to the direction of the initially applied strain. Such uniaxial waveforms have found a role in the enhancement of nanoscale fluorescence sensing [89] as an indirect biotechnological application, in addition to being applied as potential culture substrate topography. Biaxial wrinkling is achieved through the deformation of the substrate in two dimensions. Depicted in Figure 3B, the relaxation of biaxially strained sheets of oxidative plasma-treated PDMS, from which herringbone-like wrinkles were generated, is a particularly good example of generating ordered biaxial topography which does not manifest in a random crumpled arrangement [90]. Radially oriented wrinkles concentrically radiate out from a central point. Such wrinkles may be generated through the application of vapor sorption swelling on polystyrene/silicon wafer composite fine films, which results in the formation of various types of radial wrinkling patterns depending on the UVO exposure (Figure 3C and Figure 3D) [91]. Later, the use of a novel conical UVO-distribution apparatus resulted in the production of concentric wrinkles on PDMS (with radial-biaxial wrinkles at the center) [92]. The radial-biaxial patterns are the superposing of biaxial wrinkles (in horizontal plane) with radial direction (originating from a central point). These patterns arise from the inflation of the shells that are coated with a polymer solution, which is subsequently allowed to cure on the inflated surface. When the shell is relaxed, biaxial wrinkling patterns are achieved [93]. Guided pseudo-random, such structures present a randomized appearance, although having a predetermined wrinkle path formation. In a previous study, these formations used guide paths formed through photomasking to facilitate the wrinkle formation in order to produce "mazes" in trimethylolpropane ethoxylate triacrylate and 3-(trimethoxysilyl)propyl acrylate polymer [94].

The phenomenon of wrinkling discussed above encompassed the generation of only single order wrinkles. It is indeed possible to generate wrinkling patterns incorporating multiple magnitudes of wrinkles into a superstructure, and this phenomenon is termed hierarchical patterning of wrinkles. If the force on pre-stretched and UVO-treated PDMS is released slowly, a hierarchical pattern of wrinkles is observed to be generated. This patterning involves the formation of wrinkles with small wavelength (of the order of a few nanometers) initially, followed by the generation of wrinkles with larger wavelengths, which nest within the first set of generated wrinkles to produce a hierarchical pattern (refer to Figure 3E) [43]. Such patterns are replicated for five generations. Efimenko and co-workers explained this phenomenon by introducing an amplitude saturation effect, according to which the wrinkles prefer to scale-up forming a larger wavelength rather than continue folding. These complex wrinkle patterns promote a promising application of this interesting phenomenon: separation of particles of different sizes using the nested different wavelengths of wrinkles [43]. 
A)

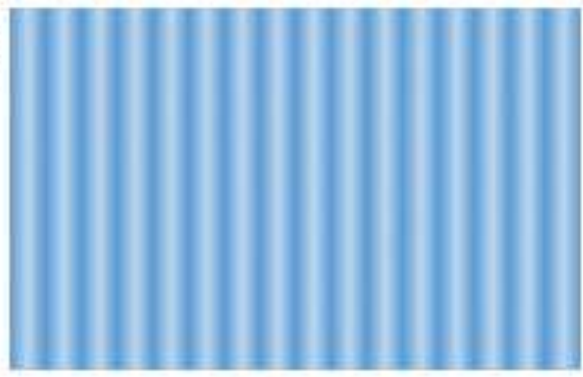

C)

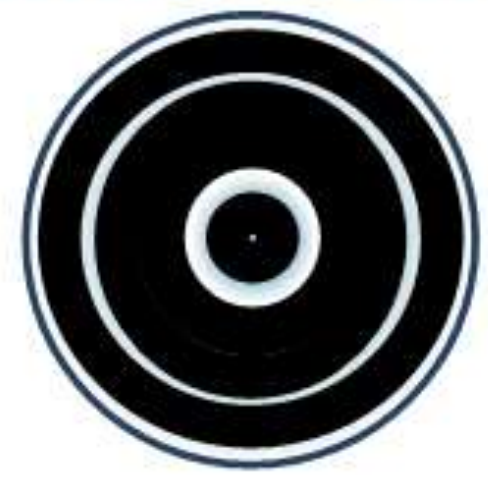

B)

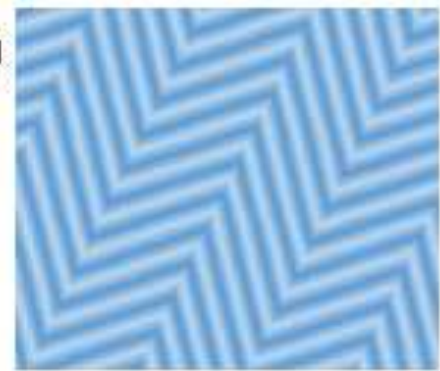

D)

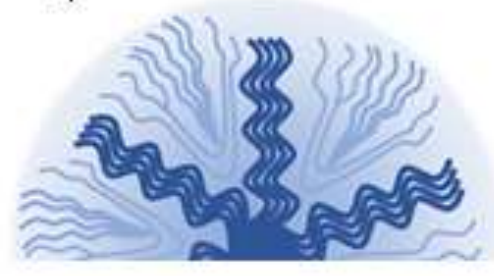

E)

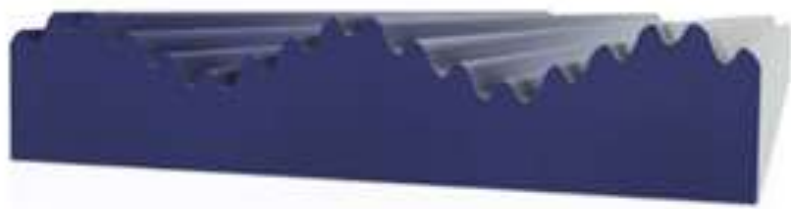

Figure 3 Illustrations of wrinkling patterns. A) Uniaxial wrinkles [88]; B) Biaxial herringbone pattern [90]; C) Radially concentric pattern [91]; D) Spoked radial pattern [91] and E) the hierarchal pattern with smaller waveforms nested within the larger wrinkles [43].

\section{Characterization and Prediction of Wrinkle Pattern}

Characterization of wrinkled materials is often performed using microscopy, particularly the scanning electron microscopy, as used in the characterization of wrinkled CuS (NIPAM-coAA) microspheres [95] in which the generated wrinkles were of the order of hundreds of micrometers. Such methods facilitate the measurement of the basic dimensions required for mathematical modeling. Subsequent to obtaining these basic dimensional measurements, determination of mechanical properties of the materials (including moduli and strain parameters) used is required, which is achieved using conventional methods which include mechanical load testing methods such as nano-indentation [96] and atomic force microscopy [97]. The principle underlying the generation of wrinkles is that the stiffness/Young's modulus of the surface layer must be far greater than that of the bulk substrate on which this layer is placed. If classical beam theory is used for describing the deflection of the surface layer and the bulk substrate is modeled as a linearly elastic and isotropic half-space, then the stiffness of the substrate is inversely proportional to the wavelength of the wrinkles [32], and as a consequence of the balance between the layer preferring large wavelength and the substrate preferring small wavelength [33], the critical wavelength $\lambda$ is expressed as: 


$$
\lambda=2 \pi h\left(\frac{\bar{E}_{s}}{3 \bar{E}_{f}}\right)^{1 / 3}
$$

where $h$ represents the layer thickness, and $E_{s}$ and $E_{f}$ represent the plane-strain Young's moduli for the layer and the bulk substrate, respectively $[39,93]$. These moduli are related to the $3 D$ Young's moduli $E_{s}$ and $E_{f}$ according to the equations $\bar{E}_{s}=E_{s} /\left(1-v_{s}{ }^{2}\right)$ and $\bar{E}_{f}=E_{f} /\left(1-v_{f}{ }^{2}\right)$, where $v_{s}$ and $v_{f}$ denote the corresponding Poisson's ratios. It is noteworthy that the above-stated formula is only the leading-order approximation which is valid when the modulus ratio $\bar{E}_{s} / \bar{E}_{f}$ is large and the non-linearity of the material, as well as the possible large deformation of the substrate, is neglected. If required, formulae having greater precision may be derived using the exact theory of non-linear elasticity $[38,39]$. When wrinkles are allowed to develop in both the directions perpendicular to the thickness of the layer, various patterns may appear depending on the material properties and on how the film/substrate structure is loaded [98-100]. The above-stated formula may be used as a predictor function which could be further incorporated into a predictive model, as discussed later in the present report. As previously discussed, several methods for achieving the desired ratio of stiffness are available. Although these methods follow completely different approaches, they all produce a common end result, i.e., the stiffening of the surface layer. When the difference in the stiffness between the surface and the bulk has been established, the body deforms inward. As discussed earlier, the method of deformation and the number of dimensions within the manipulations affect the wrinkling pattern in accordance with the method of surface modification. These parameters, therefore, form a defined set of conditions and considerations for the generation of biocompatible wrinkles (see Table 3 for a list of polymers/elastomers which may be used for polymeric wrinkling and the moduli thereof). According to the above-stated formula, the wavelength of the wrinkles is dependent on the mechanical properties of the layer and the substrate; the greater the stiffness ratio $\bar{E}_{s} / \bar{E}_{f}$, the larger is the wavelength. At given mechanical properties of the layer and the substrate, the wavelength would be proportional to the thickness of the skin. These deductions are consistent with the experimental results reported in a previous study [42], in which the wavelength and the amplitude of the wrinkles increased as the duration of plasma treatment increased because the longer duration of plasma treatment caused thickening and an increase in Young's modulus of the skin. However, the wavelength of the wrinkles is independent of the heating temperatures because of the changing compressive stress in the skin, which implies that the wavelength depends only on the inner properties of the system. On the contrary, the amplitude of the wrinkles increased with increasing heating temperature, implying higher compressive stress. Therefore, modulating the mechanical properties of materials enables the generation of wrinkles with desired wavelengths and amplitudes artificially for various applications.

Rearranging the above-stated formula, the following expression for Young's modulus of the skin is obtained:

$$
E_{s}=\left(1-v_{s}^{2}\right) \frac{3 E_{f}}{1-v_{f}^{2}}\left(\frac{\lambda}{2 \pi h}\right)^{3}
$$

The Young's modulus of an extremely thin film, which is difficult to measure using traditional 
methods, may be calculated with the aid of the above-stated formula [101, 102].

In the context of the human skin which rests on a shallow elastic substrate, the stiffness of the substrate is proportional to the wavelength squared, and consequently, the critical wavelength is expressed as follows:

$$
\lambda=\left(h H_{f}\right)^{1 / 1}\left(\frac{E_{s}}{E_{f}}\right)^{1 / 6}
$$

where $h, H_{f}, E_{s}$, and $E_{f}$ represent the thickness of the epidermis, the thickness of the dermis, Young's modulus of the epidermis, and Young's modulus of the dermis, respectively [103]. In aged skin, there are fewer and larger wrinkles compared to young skin, which may be explained by the above-stated equation, as the modulus of the upper layer of the skin would become larger as the age increases, leading to the larger wavelength of the wrinkles [104]. According to this equation, changes in Young's modulus of the epidermis caused by certain cosmetics may change the appearance of the skin. However, further research is required to determine the exact changes that would occur, since the structure of the human skin does not resemble the two-layer system completely as the interface between the epidermis and the dermis is not smooth [105].

\section{Application of Wrinkled Polymers}

\subsection{Technological Applications}

In addition to the obvious biomedical applications, there are numerous other potential uses for the wrinkled polymers. These mostly involve electronic applications of all scales. In these electronic applications, wrinkles are incorporated into a complex laminar structure of multiple coatings and layers. The largest scale application involves the fabrication of higher efficiency solar energy cells by increasing the photon capture surface area per unit area of the panel, which is achieved through the wrinkling of a PEDOT:PSS/PTB7-F20:PC ${ }_{71} \mathrm{BM} / \mathrm{ZnO} / \mathrm{ITO}$ layered system [106]. An example of an intermediate micro- and nano-scale application is the generation of wrinkles on the silver film deposited over a micropillar array. It has been demonstrated that this system is able to detect sound waves through the piezoresistive properties of the wrinkled silver coating, thereby enabling this system to be applied as an ultrasensitive pressure sensor [107]. The example of the smallest scale application is the fabrication of flexible magnetic spin valve sensors for nanoelectronics, which is achieved using a microscale layer stack that is sequentially sputtered on wrinkled PDMS. This stack is sensitive to applied magnetic fields and is able to produce detectable electrical current [108]. Although it appears that these applications are of purely industrial nature, these innovations have a significant potential for integration into the field of medical device designing. With advancements in medical technologies, the demand for smaller, smarter, and selfsufficient medical devices is on a rise. As a potential solution to the challenges arising as a consequence of this demand, wrinkled polymers facilitate the production of microscale and nanoscale sensing and electrical systems discussed above. 


\subsection{Wrinkled Surface as a Tool to Study Cell Migration}

In vivo, the cells receive multiple signals, including the chemical, mechanical, or biological ones, from the extracellular matrix (ECM). The life processes of the cells, such as growth, migration, differentiation, and death, are regulated by these signals in tandem with genetic control. The components, molecular density, and architecture of the ECM have been demonstrated to together influence cell behavior. Terms such as chemotaxis, haptotaxis, durotaxis, and galvanotaxis have been created to describe such factor-associated (solubles, chemoattractants, rigidity, electrical field, etc.) cell behaviors. Along with the study of the complex chemical signals surrounding the cells, the topography is a growing research area that may play a role in regulating the cell behaviors referred to as topotaxis [109]. Mechanotransduction is a process through which the cells deform their membranes and induce cell polarity when encountering different topographies. Mechanical signaling induced by topography may be transduced much faster compared to chemicals [110], while the integrin-binding on the cell membrane may couple to the cytoskeletal network, which extends to the nuclear scaffold, causing certain genetic regulations and changes [111]. However, the cells of varying types react differently to the same topography. For instance, melanoma cells prefer to migrate to less dense areas, while the fibroblast cells move toward more dense areas [112]. This observation may be applied as a physical method for cell sorting, having potential in medical applications.

In order to understand the mechanisms underlying the cell-topography relationships, various 2D/3D substrate structures, such as strips, grooves, sinusoidal waves, and holes, have been generated for simulating different in vivo situations. In comparison to the other sharper or smoother structures, wrinkled (sinusoidal waves) structure is more likely to resemble a natural structure, as such structural patterns already exist on the surfaces of several human organs. Therefore, in vitro wrinkle generation is useful in the study of cell behaviors in response to various topographies as well as in the in vitro culturing of organ surfaces for regenerative treatment. Introducing the cells to different surfaces with different curvatures may alter the morphology of these cells, which then may be used as a measurement for study.

Curved surfaces exist widely within the human bodies, such as in intestines, alveoli, ears, and cornea. Even then, the influence of these curved surfaces, along with that of the other properties of substrate such as chemistries, elasticity, and stiffness, on cell behavior has been underestimated for long. It has been demonstrated that curvature affects focal adhesion, cytoskeleton, and nuclear gene expression. The nucleus is believed to serve as the mechanical sensor for curvature [113]. Research has demonstrated that substrate curvature may exert an influence on the cell attachment rate, migration speed, cell morphology, and cell spread area [114]. A metric for these changes is the Cell shape index (CSI) developed by He and Jiang, which characterizes cell spreading. These measurements are useful in the characterization of the morphological changes in cells. CSI was observed to change differently between concave and convex surfaces with decreasing curvatures [115].

Different sizes of curved surfaces, ranging from the min nanoscales to large visible-to-naked-eye scales, may direct cell migration differently. At nano/microscales, which are smaller or equivalent to the size of the cell itself, the cells prefer moving along the valleys rather than over the ridges $[116,117]$. This may be explained by the internal actin polymerization waves guiding the migration in the direction of both pseudopod-dominated and lamellipodia-driven migrations [118]. When 
the scale increases, the effect of curvature, termed as curvotaxis, comes into play [119]. Concave surfaces are thought to modulate the direction of cell migration through protrusion force better than the convex surfaces. Increasing the concave curvature increases the protrusion force along the long axis, promoting cell migration along the long axis. Without such force, cell polarization may fail to generate directional migration, as is the case with convex surfaces [115].

Certain other models have been developed to simulate cell migration on curved surfaces in order to analyze the mechanical situations for substrate-guided cell migration [119-121]. All these models are based on simplified experimentally-obtained results, are partly validated, and therefore, require further experimental investigation to confirm their authenticity. It has been observed that cell migration speed is greater on a concave surface compared to a convex substrate, while the convex substrates appear to promote cell differentiation through nuclear deformation. This may be explained by the process of cell migration, in which the cells on a concave substrate prefer to stretch upward and reduce contact with the substrate, causing the migration process to be faster [122]. This observation is consistent with the model discussed earlier, demonstrating that cell migration is more persistent and the protrusion force in the direction of migration is larger on the concave surfaces, while cell spreading is greater on convex surfaces [115]. With the application of wrinkled polymer surface techniques, it becomes convenient to fabricate curved surface substrates with a tunable curvature that matches the cellular dimensions, for the study of cell migration.

\subsection{Predictive Models and Diagnostic Tools}

Using an amalgamation of modeling and practical approaches, it may be possible to apply the principles utilized in the characterization of the wrinkles for pathological diagnostic purposes. Computational methods may be used to simulate wrinkling, and to generate surface and bulk strain plots which are comparable to human skin tissue structure, as in the in silico modeling of skin microrelief and microwrinkles [123]. A pure modeling example of this is the use of finite element modeling, which utilizes neo-Hookean laws to predict the effects of surface wetness and stratus corneum age on skin wrinkling, in relation to aging. This particular study utilized a trilayer replicative model of stratum corneum, epidermis, and the deep dermis, employing in silico methods based on the data obtained from the literature [124]. Using similar methods, it was determined that in addition to wetting and aging, the changes in the thickness and modulus of the stratum corneum also influenced the mechanical properties of the skin, which was evident through the changes in the periodicity of the simulated wrinkling [125]. In a practical context, an association of loss of skin elasticity, measured through skin visco-elasticity testing and scoring of facial wrinkling, has been observed with a decline in the pulmonary health derivative of smoking [126]. Such an association provides the premise for the use of skin wrinkling and the characterization of these wrinkles as a potential biomarker for poor health. In another study, which analyzed the effect of hormone therapy on age-related skin changes in postmenopausal women, wrinkling alongside sagging was used as a measure of skin quality. As a part of the assessment regimen, the depth of skin wrinkling (determined through images) was utilized as a metric to assess the degree of any changes that occurred in the skin structure, and its values were then compared between the hormone-treated and the placebo-treated groups [127]. In consideration of these applications of skin measurements, it is plausible to apply both the approaches so as to 
produce an in silico model for skin-related disease progression using wrinkle measurements as an input metric for predictive functionality. Such models would have direct clinical as well as industrial applications.

\subsection{Applications in Cosmetic Industry}

A direct industrial application of polymer wrinkling and wrinkling principles is the modeling of skin for the cosmetics industry. Skin models produced for this purpose would be of value as they would be able to predict the cosmetic product's viability and safety in a human model without the requirement for animal testing. Previous studies concerning the characterization of wrinkling in human skin are available in the literature, for example, the use of finite element modeling of the human forearm skin [128] and the application of histological staining to visualize wrinkling and characterize the cell types present in the skin tissue [129]. These characterizations enable creating in vitro organotypic models of the skin surface using microfluidic systems and then compare them with both in vivo and control sections for drug testing [130]. In the context of wrinkling, these models did not generate the skin surface wrinkling which was representative of the normal tissue in the controls and in vivo. Although it is possible to maintain the biomimetic topography in a static fashion [131], it does not provide the structural support necessary for the rigorous mechanical or aggressive surface testing that is required for the models to be applicable in the cosmetics industry. This is where the wrinkled polymers as culture substrates could play a crucial role, and with the incorporation of the principles utilized in all the aforementioned studies, it would be possible to develop a representative human skin model that is industry-relevant.

\subsection{Antibacterial Applications of Wrinkled and Wrinkle-Like Topographies}

Studies involving the application of wrinkle-like topography have been conducted to determine the effect of different types of topographies on bacterial adhesion [132, 133]. These studies included the uniaxial grooved channels, which (as first demonstrated in the previous study, and confirmed in another) upon the seeding of three different bacterial cultures exhibited a modulatory effect on the adhesion properties of these bacteria. It could be inferred from these studies that the application of topographies, including the wrinkle-like channels, confer the ability to the cells to select their initial seeding position, thereby affecting their adhesion properties and consequently the formation of biofilms. Besides the context of uniaxial wrinkling, bacterial adhesion has also been explored in the culturing of Staphylococcus epidermidis on biaxiallywrinkled polyurea/urethane surfaces, and it was highlighted that the wrinkled surfaces facilitated better bacterial cell adhesion compared to the smooth elastomeric surfaces. However, it is possible to modulate the amount of cell adhesion on the basis of the amount of mechanical surface stretching and UV surface treatment [133]. An example of the use of bacterial studies on uniaxial wrinkled topography is the characterization of the adhesion properties of $P$. aeruginos $a$ on flat and wrinkled PDMS surfaces generated through oxygen plasma treatment and mechanical stretching, which revealed that the wrinkled surfaces facilitated better bacterial cell adhesion and spatial arrangement compared to the smooth surfaces [134]. All these studies reached a common conclusion that surface topography may be able to significantly affect bacterial adhesion. This has serious implications as it conveys that it is possible to have dynamic and selective anti-bacterial systems having valuable potential applications in both industrial and medical fields. 


\subsection{Control of Cell's Activities Using Wrinkles in Tissue Engineering}

In a biological context, wrinkles have multiple facets. They may be considered for their structural role, such as the tissue undulations which form the working architecture of that particular tissue for its required function; this was appreciated in the analysis of collagen and elastin fibers in arterial adventitia [135] and in the quantitative analysis of the basement membrane-supported epithelial cell sheet folding [136]. In addition to the physical/structural properties of the wrinkled tissues, the enclosure, separation, and bounding of the tissue-specific microenvironments formed through wrinkling may be evaluated using various methods including histology [137], RNA sequencing [138], and biochemical analyses [139]. Each type of tissue analysis has its own niche of applications, although all are applicable to the field of characterizing undulating/wrinkled tissue and engineered constructs. Wrinkles may also be considered in the regulatory context, particularly the manner in which wrinkling and the subsequent tissue mechanics correlate to the function and behavior of that tissue in terms of cell signaling [140], mechanobiology [141], cell fate determination [142], and the regulation of cell movement [143]. In the view of this appreciation of the wrinkling phenomenon in the biological context, it is highly plausible to perceive value in the replication of the natural phenomenon. This is particularly true in case of self-regulating cellular applications that are more accurately biologically representative in comparison to the other existing methods for micro-patterning polymer surfaces such as the use of micropatterned PLGA to study nuclear deformation in osteosarcoma cells [1].

Cellular alignment over the topography of a surface, as stated earlier, is a common effect upon the introduction of cells to a particular topography, whereby the cells, because of their flexible and motile nature, conform, adapt, and settle over the shapes. This effect is no different in the wrinkled substrates. In this context, grooved and trench topographies serve the same purpose and demonstrate the same directional collimation in the alignment of cells. Examples of this include the alignment of smooth muscle cells between the melt-spun PCL fibers [144]. This effect is also observed in shape-memory PCL surfaces which exhibit dynamic cell orientation over the nanowrinkles created on these surfaces [145].

When cells are grown on an undulating or wrinkled substrate, morphological differences are observed manifesting in these cells when they are introduced to wrinkled topographies, as depicted in Figure 4. These cells present a distinct change in their morphology, where the multidirectional spread-out morphology of the cells usually observed in the 2D culture evolves into a wrinkle-collimated stretched pilus morphology. The cells expand within and along the constraints of the valley-like shapes of the wrinkled topography, perpendicular to the wrinkle waveform propagation. Such cellular deformation has been demonstrated for mouse and human fibroblasts in the wrinkling of graphene-coated pre-stretched PDMS, where such morphological changes were observed alongside high levels of cellular alignment within the wrinkles [146]. Another example is the wrinkling of the PDMS substrate using UV and ozone treatment on the pre-stretched substrate, which wrinkled upon relaxation. Subsequently, human mesenchymal stem cells were seeded over the wrinkled substrate, and the certain challenges to morphology and alignment were observed [44]. In addition to exerting an effect on the morphology of cells placed over a wrinkled substrate, wrinkles have been demonstrated to affect the phenotypic expression of cells. This effect was observed in macrophages which exhibited modulation in the expressions of aginase-1, IL -10 , and TNF- $\alpha$ as a result of cell shape deformation induced by the wrinkled substrate [147]. 

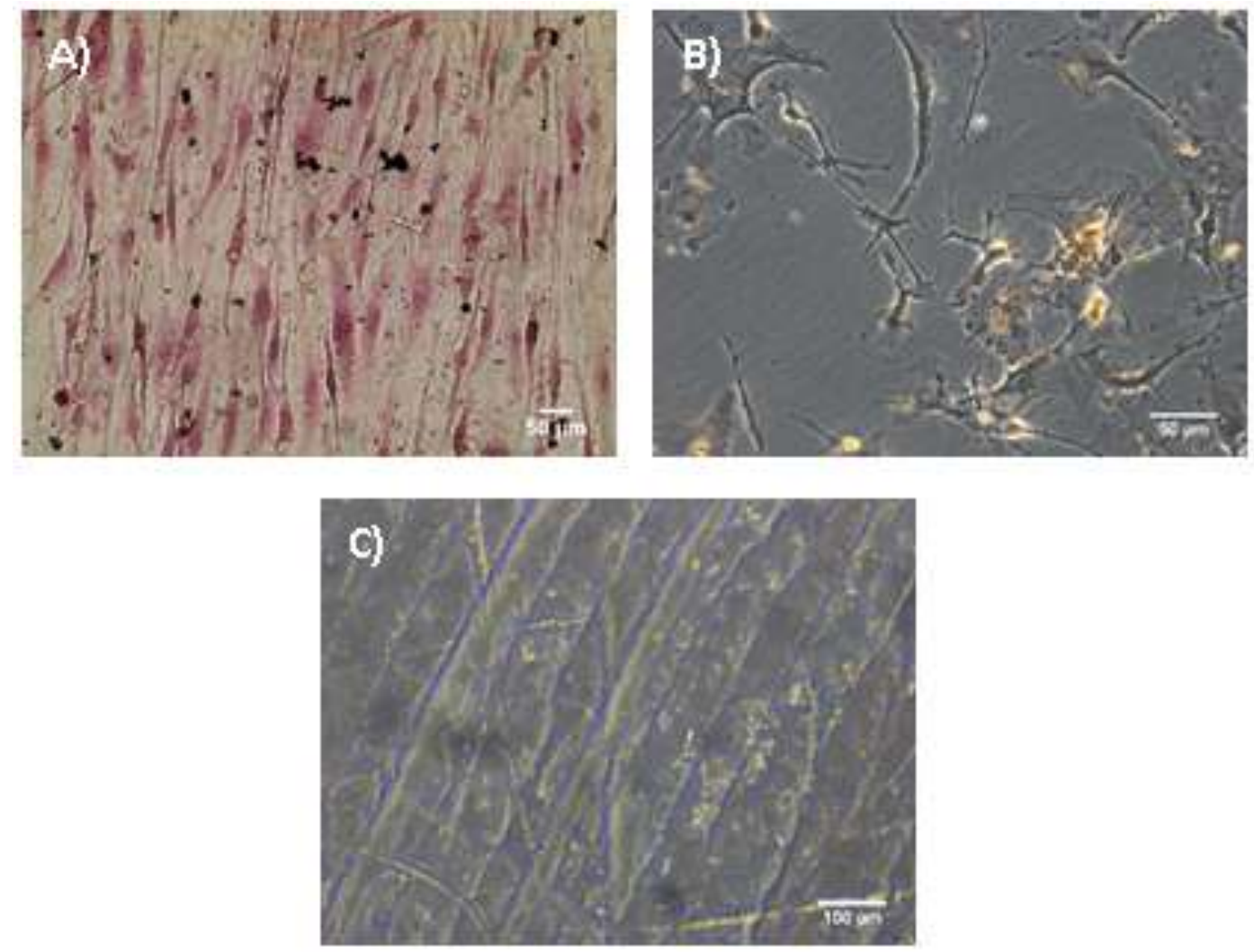

Figure 4 Mouse neonatal cardiomyoblasts aligned over oxygen plasma-treated wrinkled PDMS. A) cells stained with Hematoxylin \& Eosin showing both alignment and pili morphology induction. B) Control cells on tissue culture plastic. C) Clean wrinkled PDMS before being seeded with cells.

\section{Concluding Remarks}

Wrinkles are formed due to instabilities in the systems consisting of different materials, and the final patterns developed in the system are the best choice for that particular system to have the lowest possible potential energy [104]. Wrinkling is a universal phenomenon observed widely in nature, from the aging human skin to the shrinking of fruits to huge deformations in the earth's crust. The two-layered system just scratches the surface of the principles and mechanisms underlying wrinkle formation, as the research on wrinkling is currently far from mature, even though the topographical features created through wrinkling are in high demand in various fields. Such demands are particularly profound in the biomedical sciences, where these features may be utilized in biological regulation and therapeutic implementation strategies. The wrinkle fabrication techniques are simple and cost-effective in comparison to other techniques such as lithography. The wrinkling techniques discussed in the present report also have the added advantage of achieving a higher structural complexity compared to the other currently available techniques. Approaches concerning the prediction of complicated wrinkle patterns on various materials are yet to be explored, especially in case of in vivo biomedical applications rather than the in vitro experimentation and computational modeling. Models with greater precision which are able to explain the compressive stress generated in the skin in relation to various situations and patterns are required in order to be able to modulate the wrinkles effectively. The biomedical applications 
of wrinkling polymers exhibit exciting prospects for several fields, especially tissue engineering, clinical (and industrial) dermatology, and medical device engineering. In addition, challenges in the progression of this field are required to be addressed. The most important among these challenges is the reproducibility of the modeled wrinkled topographies, their properties, and the effects that they (intended and otherwise) impose upon the biological systems and the biomedical device design and evolution, which are yet to be investigated. Nonetheless, efforts for direct biomedical applications are being made. The dynamics involved in the mechanical strain-induced wrinkle formation unlocks a diverse field of smart applications in biological systems that apply multiple dynamic mechanisms for natural hemostasis. A recent report describing the development of antithrombotic materials is an excellent example of the novel use of wrinkling in an emerging biomedical application [148]. The antibacterial application of wrinkled polymer surfaces is another such example. As discussed previously, these techniques facilitate the advancement of the field in novel directions. With advancements in the field of biomedical applications of the wrinkled polymers, increasing contributions from a greater diversity of other fields, and the integration of complex novel ideas and biologically representative systems, it would be possible to develop viable biomedical therapeutic products and devices.

\section{Author Contributions}

RLD: Writing-original draft preparation, Reviewing and Editing; XYLW: Writing-original draft preparation, reviewing and editing; YBF: Writing-reviewing and editing; AJEH: Writing-reviewing and editing; YY: Conceptualization, writing-reviewing and editing.

\section{Funding}

This research is funded by the Engineering and Physical Sciences Research Council (EPSRC), UK, Center for doctor training in Regenerative medicine.

\section{Competing Interests}

The authors have declared that no competing interests exist.

\section{References}

1. Antmen E, Ermis M, Demirci U, Hasirci V. Engineered natural and synthetic polymer surfaces induce nuclear deformation in osteosarcoma cells. J Biomed Mater Res B Appl Biomater. 2019; 107: 366-376.

2. Renkawitz J, Reversat A, Leithner A, Merrin J, Sixt M. Micro-engineered "pillar forests" to study cell migration in complex but controlled 3D environments. Methods Cell Biol. 2018; 147: 79-91.

3. Haaf F, Sanner A, Straub F. Polymers of N-vinylpyrrolidone: Synthesis, characterization and uses. Polym J. 1985; 17: 143-152.

4. Back D, Schmitt R. Encyclopedia of polymer science and technology. 2004.

5. Tasdelen MA, Moszner N, Yagci Y. The use of poly (ethylene oxide) as hydrogen donor in type II photoinitiated free radical polymerization. Polym Bull. 2009; 63: 173-183. 
6. Miszuk JM, Xu T, Yao Q, Fang F, Childs JD, Hong Z, et al. Functionalization of PCL-3D electrospun nanofibrous scaffolds for improved BMP2-induced bone formation. Appl Mater Today. 2018; 10: 194-202.

7. Bao C, Chong MS, Qin L, Fan Y, Teo EY, Sandikin D, et al. Effects of tricalcium phosphate in polycaprolactone scaffold for mesenchymal stem cell-based bone tissue engineering. Mater Technol. 2019; 34: 361-367.

8. Yoshimoto I, Sasaki JI, Tsuboi R, Yamaguchi S, Kitagawa H, Imazato S. Development of layered PLGA membranes for periodontal tissue regeneration. Dent Mater J. 2018; 34: 538-550.

9. Qi Z, Guo W, Zheng S, Fu C, Ma Y, Pan S, et al. Enhancement of neural stem cell survival, proliferation and differentiation by IGF-1 delivery in graphene oxide-incorporated PLGA electrospun nanofibrous mats. RSC Adv. 2019; 9: 8315-8325.

10. Rabaeh KA, Al-Ajaleen MS, Abuzayed MH, Aldweri FM, Eyadeh MM. High dose sensitivity of N(isobutoxymethyl) acrylamide polymer gel dosimeters with improved monomer solubility using acetone co-solvent. Nucl Instrum Methods Phys Res B. 2019; 442: 67-72.

11. Buckley $C$, Jones $D$, Jones D. Hot-drawing of poly (ethylene terephthalate) under biaxial stress: Application of a three-dimensional glass-rubber constitutive model. Polymer. 1996; 37: 2403-2414.

12. Aufderheide $M$, Horlebein A, Tauscher $M$. Comparison of cytoskeletal structures in glassadherent and polyethylene terephthalate (PET) membrane-adherent human pulmonary fibroblasts. Exp Toxicol Pathol. 1999; 51: 3-7.

13. Lin S, Bhattacharyya D, Fakirov S, Cornish J. Novel organic solvent free micro-/nano-fibrillar, nanoporous scaffolds for tissue engineering. Int J Polym Mater Polym Biomater. 2014; 63: 416-423.

14. Gubanski S. Modern outdoor insulation-concerns and challenges. IEEE Electr Insul M. 2005; 21: 5-11.

15. Yin $Y$, Zhang $Y$, Chen $X$, Liu S, Jiang $X$, Chi Z, et al. Environment-friendly silicone sealants by self-catalytic cross-linking reaction of $\alpha$-aminomethyl triethoxysilanes. Polym Eng Sci. 2011; 51: 1033-1040.

16. Xu X, Ma L, Wu Y, Tang L. Micropillar-based culture platform induces epithelial-mesenchymal transition in the alveolar epithelial cell line. J Biomed Mater Res A. 2018; 106: 3165-3174.

17. Zaky SH, Lee KW, Gao J, Jensen A, Close J, Wang Y, et al. Poly (glycerol sebacate) elastomer: A novel material for mechanically loaded bone regeneration. Tissue Eng Part A. 2014; 20: 45-53.

18. de Haan LT, Leclère $P$, Damman $P$, Schenning AP, Debije MG. On-demand wrinkling patterns in thin metal films generated from self-assembling liquid crystals. Adv Funct Mater 2015; 25: 1360-1365.

19. Chen TL, Huang CY, Xie YT, Chiang YY, Chen Y-M, Hsueh H-Y. Bioinspired durable superhydrophobic surface from a hierarchically wrinkled nanoporous polymer. ACS Appl Mater Interfaces. 2019; 11: 40875-40885.

20. Torres JM, Stafford CM, Vogt BD. Elastic modulus of amorphous polymer thin films: Relationship to the glass transition temperature. Acs Nano. 2009; 3: 2677-2685.

21. Batisse D, Bazin R, Baldeweck T, Querleux B, Lévêque JL. Influence of age on the wrinkling capacities of skin. Skin Res Technol. 2002; 8: 148-154.

22. Chandra A, Thangavelautham J. Modular inflatable composites for space telescopes. 2019 IEEE Aerospace Conference; 2019. 
23. Martinez-Campos E, Gallardo A, Lujan N, Santos-Coquillat A, Reinecke H, Campo Ad, et al. Wrinkled hydrogel surfaces with modulated surface chemistry and topography: Evaluation as supports for cell growth and transplant. ACS Appl Bio Mater. 2019; 2: 654-664.

24. Chen $\mathrm{CM}$, Yang S. Wrinkling instabilities in polymer films and their applications. Polym Int. 2012; 61: 1041-1047.

25. Schweikart A, Fery A. Controlled wrinkling as a novel method for the fabrication of patterned surfaces. Mikrochim Acta. 2009; 165: 249-263.

26. Bowden N, Brittain S, Evans AG, Hutchinson JW, Whitesides GM. Spontaneous formation of ordered structures in thin films of metals supported on an elastomeric polymer. Nature. 1998; 393: 146-149.

27. Costa RG, Caro PL, de Matos-Neto EM, Lima JD, Radloff K, Alves MJ, et al. Cancer cachexia induces morphological and inflammatory changes in the intestinal mucosa. J Cachexia Sarcopenia Muscle. 2019; 10: 1116-1127.

28. Donne ML, Lechner AJ, Rock JR. Evidence for lung epithelial stem cell niches. BMC Dev Biol. 2015; 15: 32.

29. Mwale F, Wang HT, Nelea V, Luo L, Antoniou J, Wertheimer MR. The effect of glow discharge plasma surface modification of polymers on the osteogenic differentiation of committed human mesenchymal stem cells. Biomaterials. 2006; 27: 2258-2264.

30. Kim HN, Kang DH, Kim MS, Jiao A, Kim D-H, Suh K-Y. Patterning methods for polymers in cell and tissue engineering. Ann Biomed Eng. 2012; 40: 1339-1355.

31. Schwartz E, Brown C. An investigation of the compressive strength properties of stainless steel sheet-stringer combinations. Air service information circular, volume 7, number 697 . Air Force Research Lab Wright-Patterson AFB OH Wright Research Site; 1934.

32. Biot MA. Bending of an infinite beam on an elastic foundation. J Appl Math Mech. 1922; 2: 165-184.

33. Allen HG. Analysis and design of structural sandwich panels: The commonwealth and international library: Structures and solid body mechanics division. Elsevier; 2013.

34. Shanley F. Elastic theory in sheet metal forming problems. J Aeronaut Sci. 1942; 9: 313-333.

35. Wu CH. Nonlinear wrinkling of nonlinear membranes of revolution. J Appl Mech. 1978; 45: 533-538.

36. Jortner J. A model for predicting thermal and elastic constants of wrinkled regions in composite materials. Effects of Defects in Composite Materials: ASTM International; 1984.

37. Zhang L, Yu T. Modified adaptive dynamic relaxation method and its application to elasticplastic bending and wrinkling of circular plates. Comput Struct. 1989; 33: 609-614.

38. Cai Z, Fu Y. On the imperfection sensitivity of a coated elastic half-space. Proc Math Phys Eng Sci. 1999; 455: 3285-3309.

39. Cai Z, Fu Y. Effects of pre-stretch, compressibility and material constitution on the perioddoubling secondary bifurcation of a film/substrate bilayer. Int J Non Linear Mech. 2019; 115: 11-19.

40. Kim JB, Kim P, Pégard NC, Oh SJ, Kagan CR, Fleischer JW, et al. Wrinkles and deep folds as photonic structures in photovoltaics. Nat Photonics. 2012; 6: 327.

41. Lee SG, Kim H, Choi HH, Bong H, Park YD, Lee WH, et al. Evaporation-induced self-alignment and transfer of semiconductor nanowires by wrinkled elastomeric templates. Adv Mater. 2013; 25: 2162-2166. 
42. Bowden N, Huck WT, Paul KE, Whitesides GM. The controlled formation of ordered, sinusoidal structures by plasma oxidation of an elastomeric polymer. Appl Phys Lett. 1999; 75: 25572559.

43. Efimenko K, Rackaitis M, Manias E, Vaziri A, Mahadevan L, Genzer J. Nested self-similar wrinkling patterns in skins. Nat Mater. 2005; 4: 293-297.

44. Guvendiren M, Burdick JA. Stem cell response to spatially and temporally displayed and reversible surface topography. Adv Healthc Mater. 2013; 2: 155-164.

45. Ohzono T, Shimomura M. Simulation of strain-induced microwrinkle pattern dynamics with memory effect. Jpn J Appl Phys. 2005; 44: 1055.

46. Glatz BA, Fery A. The influence of plasma treatment on the elasticity of the in situ oxidized gradient layer in PDMS: Towards crack-free wrinkling. Soft Matter. 2019; 15: 65-72.

47. Lin P-C, Yang S. Spontaneous formation of one-dimensional ripples in transit to highly ordered two-dimensional herringbone structures through sequential and unequal biaxial mechanical stretching. Appl Phys Lett. 2007; 90: 241903.

48. Chau K, Millare B, Lin A, Upadhyayula S, Nuñez V, Xu H, et al. Dependence of the quality of adhesion between poly (dimethylsiloxane) and glass surfaces on the composition of the oxidizing plasma. Microfluid Nanofluidics. 2011; 10: 907-917.

49. Prajzler V, Nekvindova P, Spirkova J, Novotny M. The evaluation of the refractive indices of bulk and thick polydimethylsiloxane and polydimethyl-diphenylsiloxane elastomers by the prism coupling technique. J Mater Sci. 2017; 28: 7951-7961.

50. Zong C, Zhao Y, Ji H, Han X, Xie J, Wang J, et al. Tuning and erasing surface wrinkles by reversible visible-light-induced photoisomerization. Angew Chem Int Ed Engl. 2016; 55: 39313935.

51. Zong C, Zhao Y, Ji H, Xie J, Han X, Wang J, et al. Patterning surfaces on azo - based multilayer films via surface wrinkling combined with visible light irradiation. Macromol Rapid Commun. 2016; 37: 1288-1294.

52. Chen $X$, Hutchinson JW. Herringbone buckling patterns of compressed thin films on compliant substrates. J Appl Mech. 2004; 71: 597-603.

53. Greco F, Bellacicca A, Gemmi M, Cappello V, Mattoli V, Milani P. Conducting shrinkable nanocomposite based on Au-nanoparticle implanted plastic sheet: Tunable thermally induced surface wrinkling. ACS Appl Mater Interfaces. 2015; 7: 7060-7065.

54. Al-Nimr M. Heat transfer mechanisms during short-duration laser heating of thin metal films. Int J Thermophys. 1997; 18: 1257-1268.

55. Yin J, Han X, Cao Y, Lu C. Surface wrinkling on polydimethylsiloxane microspheres via wet surface chemical oxidation. Sci Rep. 2014; 4: 5710.

56. Aufan MR, Sumi Y, Kim S, Lee JY. Facile synthesis of conductive polypyrrole wrinkle topographies on polydimethylsiloxane via a swelling-deswelling process and their potential uses in tissue engineering. ACS Appl Mater Interfaces. 2015; 7: 23454-23463.

57. Juřík $P$, Slepička $P$, Nagyová $M$, Švorčík V. Wrinkle pattern on PLLA induced by stress of polymer-metal bilayer. Surf Coat Technol. 2017; 311: 344-350.

58. Suchentrunk R, Fuesser H, Staudigl G, Jonke D, Meyer M. Plasma surface engineeringinnovative processes and coating systems for high-quality products. Surf Coat Technol. 1999; 112: 351-357. 
59. Hillborg H, Karlsson S, Gedde UW. Characterisation of low molar mass siloxanes extracted from crosslinked polydimethylsiloxanes exposed to corona discharges. Polymer. 2001; 42: 8883-8889.

60. Yan XZ, van den Beucken JJ, Yuan C, Jansen JA, Yang F. Evaluation of polydimethylsiloxanebased substrates for in vitro culture of human periodontal ligament cells. J Biomed Mater Res A. 2019; 107: 2796-2805.

61. Yousefi SZ, Tabatabaei-Panah PS, Seyfi J. Emphasizing the role of surface chemistry on hydrophobicity and cell adhesion behavior of polydimethylsiloxane/TiO2 nanocomposite films. Colloids Surf B Biointerfaces. 2018; 167: 492-498.

62. Koppes AN, Kamath M, Pfluger CA, Burkey DD, Dokmeci M, Wang L, et al. Complex, multiscale small intestinal topography replicated in cellular growth substrates fabricated via chemical vapor deposition of Parylene C. Biofabrication. 2016; 8: 035011.

63. Guillemette MD, Roy E, Auger FA, Veres T. Rapid isothermal substrate microfabrication of a biocompatible thermoplastic elastomer for cellular contact guidance. Acta Biomater. 2011; 7 : 2492-2498.

64. Prabhakaran MP, Nair AS, Kai D, Ramakrishna S. Electrospun composite scaffolds containing poly (octanediol-co-citrate) for cardiac tissue engineering. Biopolymers. 2012; 97: 529-538.

65. Kocgozlu L, Lavalle P, Koenig G, Senger B, Haikel Y, Schaaf $P$, et al. Selective and uncoupled role of substrate elasticity in the regulation of replication and transcription in epithelial cells. J Cell Sci. 2010; 123: 29-39.

66. Nezakati T, Tan A, Lim J, Cormia RD, Teoh S-H, Seifalian AM. Ultra-low percolation threshold POSS-PCL/graphene electrically conductive polymer: Neural tissue engineering nanocomposites for neurosurgery. Mater Sci Eng C Mater Biol Appl. 2019; 104: 109915.

67. Amerian $M$, Amerian $M$, Sameti $M$, Seyedjafari $E$. Improvement of PDMS surface biocompatibility is limited by the duration of oxygen plasma treatment. J Biomed Mater Res A. 2019; 107: 2806-2813.

68. Richardson SA, Rawlings TM, Muter J, Walker M, Brosens JJ, Cameron NR, et al. Covalent attachment of fibronectin onto emulsion-templated porous polymer scaffolds enhances human endometrial stromal cell adhesion, infiltration, and function. Macromol Biosci. 2019; 19: 1800351.

69. Chae SS, Jung JH, Choi WJ, Park JK, Baik HK, Jung J, et al. Multilayer fabrication of unobtrusive poly (dimethylsiloxane) nanobrush for tunable cell adhesion. Sci Rep. 2019; 9: 1-10.

70. Ban $M$, Kogi $Y$, Hirose T. Fabrication of arrayed microwells with wrinkle microstructure by inkjet and diamond-like carbon thin film deposition process. Mater Sci Eng B Solid State Mater Adv Technol. 2019; 249: 114422.

71. Wu L, Magaz A, Wang T, Liu C, Darbyshire A, Loizidou M, et al. Stiffness memory of indirectly 3D-printed elastomer nanohybrid regulates chondrogenesis and osteogenesis of human mesenchymal stem cells. Biomaterials. 2018; 186: 64-79.

72. Zia KM, Zuber M, Bhatti IA, Barikani M, Sheikh MA. Evaluation of biocompatibility and mechanical behavior of polyurethane elastomers based on chitin/1, 4-butane diol blends. Int J Biol Macromol. 2009; 44: 18-22.

73. Bernacca GM, O'Connor B, Williams DF, Wheatley DJ. Hydrodynamic function of polyurethane prosthetic heart valves: Influences of Young's modulus and leaflet thickness. Biomaterials. 2002; 23: 45-50. 
74. Yang J, Webb AR, Pickerill SJ, Hageman G, Ameer GA. Synthesis and evaluation of poly (diol citrate) biodegradable elastomers. Biomaterials. 2006; 27: 1889-1898.

75. Liang K, Zhou Y, Ji Y. Full biodegradable elastomeric nanocomposites fabricated by chitin nanocrystal and poly (caprolactone-diol citrate) elastomer. J Bioact Compat Polym. 2019; 34: 453-463.

76. Choi SH, Park TG. Synthesis and characterization of elastic PLGA/PCL/PLGA tri-block copolymers. J Biomater Sci Polym Ed. 2002; 13: 1163-1173.

77. Chan JM, Zhang L, Yuet KP, Liao G, Rhee J-W, Langer R, et al. PLGA-lecithin-PEG core-shell nanoparticles for controlled drug delivery. Biomaterials. 2009; 30: 1627-1634.

78. Ion R, Pollock $\mathrm{H}$, Roques-Carmes $\mathrm{C}$. Micron-scale indentation of amorphous and drawn PET surfaces. J Mater Sci. 1990; 25: 1444-1454.

79. Esena P, Riccardi C, Zanini S, Tontini M, Poletti G, Orsini F. Surface modification of PET film by a DBD device at atmospheric pressure. Surf Coat Technol. 2005; 200: 664-667.

80. Kollar J, Morelli A, Chiellini F, Miertus S, Bakos D, Frecer V. Epithelial cell adhesion on films mimicking surface of polymeric scaffolds of artificial urethra compared to molecular modeling of integrin binding. J Bioact Compat Polym. 2019; 34: 280-290.

81. Zhang HW, Hu XB, Qin Y, Jin ZH, Zhang XW, Liu YL, et al. Conductive polymer coated scaffold to integrate 3D cell culture with electrochemical sensing. Anal Chem. 2019; 91: 4838-4844.

82. Rogers AJ, Miller JM, Kannappan R, Sethu P. Cardiac tissue chips (CTCS) for modeling cardiovascular disease. IEEE Trans Biomed Eng. 2019; 66: 3436-3443.

83. Agrawal A, Adetiba O, Kim H, Chen H, Jacot JG, Verduzco R. Stimuli-responsive liquid crystal elastomers for dynamic cell culture. J Mater Res. 2015; 30: 453-462.

84. Yang J, Webb AR, Ameer GA. Novel citric acid-based biodegradable elastomers for tissue engineering. Adv Mater. 2004; 16: 511-516.

85. Stankus JJ, Guan J, Fujimoto K, Wagner WR. Microintegrating smooth muscle cells into a biodegradable, elastomeric fiber matrix. Biomaterials. 2006; 27: 735-744.

86. Huck WT, Bowden N, Onck P, Pardoen T, Hutchinson JW, Whitesides GM. Ordering of spontaneously formed buckles on planar surfaces. Langmuir. 2000; 16: 3497-3501.

87. UweáClaussen K. Towards tailored topography: Facile preparation of surface-wrinkled gradient poly (dimethyl siloxane) with continuously changing wavelength. RSC Adv. 2012; 2: 10185-10188.

88. Sun JY, Xia S, Moon MW, Oh KH, Kim KS. Folding wrinkles of a thin stiff layer on a soft substrate. Proc Math Phys Eng Sci. 2012; 468: 932-953.

89. Fu CC, Grimes A, Long M, Ferri CG, Rich BD, Ghosh S, et al. Tunable nanowrinkles on shape memory polymer sheets. Adv Mater. 2009; 21: 4472-4476.

90. Zhang YJ, Yu SJ, Chen MG, Cai PG, Zhou H. Impurity induced wrinkling patterns in metal films deposited on soft elastic substrates. Surf Rev Lett. 2017; 24: 1750034.

91. Chung JY, Nolte AJ, Stafford CM. Diffusion-controlled, self-organized growth of symmetric wrinkling patterns. Adv Mater. 2009; 21: 1358-1362.

92. Li $H$, Sheng $B$, Wu H, Huang $Y$, Zhang $D$, Zhuang $S$. Ring wrinkle patterns with continuously changing wavelength produced using a controlled-gradient light field. Materials. 2018; 11: 1571. 
93. Al-Rashed R, Jiménez FL, Marthelot J, Reis PM. Buckling patterns in biaxially pre-stretched bilayer shells: Wrinkles, creases, folds and fracture-like ridges. Soft Matter. 2017; 13: 79697978.

94. Bae HJ, Bae S, Yoon J, Park C, Kim K, Kwon S, et al. Self-organization of maze-like structures via guided wrinkling. Sci Adv. 2017; 3: e1700071.

95. Yang J, Fang Y, Bai C, Hu D, Zhang Y. CuS-poly (N-isopropylacrylamide-co-acrylic acid) composite microspheres with patterned surface structures: Preparation and characterization. Chi Sci Bull. 2004; 49: 2026-2032.

96. Odegard G, Gates T, Herring H. Characterization of viscoelastic properties of polymeric materials through nanoindentation. Exp Mech. 2005; 45: 130-136.

97. Kibena E, Mooste M, Kozlova J, Marandi M, Sammelselg V, Tammeveski K. Surface and electrochemical characterisation of CVD grown graphene sheets. Electrochem commun. 2013; 35: 26-29.

98. Volynskii A, Bazhenov S, Lebedeva O, Bakeev N. Mechanical buckling instability of thin coatings deposited on soft polymer substrates. J Mater Sci. 2000; 35: 547-554.

99. Audoly B, Boudaoud A. Buckling of a stiff film bound to a compliant substrate-Part II: A global scenario for the formation of herringbone pattern. J Mech Phys Solids. 2008; 56: 24222443.

100.Audoly B, Boudaoud A. Buckling of a stiff film bound to a compliant substrate-Part I: Formulation, linear stability of cylindrical patterns, secondary bifurcations. J Mech Phys Solids. 2008; 56: 2401-2421.

101.Li B, Cao YP, Feng XQ, Gao H. Mechanics of morphological instabilities and surface wrinkling in soft materials: A review. Soft Matter. 2012; 8: 5728-5745.

102.Stafford CM, Harrison C, Beers KL, Karim A, Amis EJ, VanLandingham MR, et al. A bucklingbased metrology for measuring the elastic moduli of polymeric thin films. Nat Mater. 2004; 3 : 545-550.

103.Cerda E, Mahadevan L. Geometry and physics of wrinkling. Phys Rev Lett. 2003; 90: 074302.

104.Serup J, Jemec GB, Grove GL. Handbook of non-invasive methods and the skin. CRC press; 2006.

105. Magnenat-Thalmann N, Kalra P, Leveque JL, Bazin R, Batisse D, Querleux B. A computational skin model: Fold and wrinkle formation. IEEE Trans Inf Technol Biomed. 2002; 6: 317-323.

106.Ryu SY, Seo JH, Hafeez H, Song M, Shin JY, Kim DH, et al. Effects of the wrinkle structure and flat structure formed during static low-temperature annealing of $\mathrm{ZnO}$ on the performance of inverted polymer solar cells. J Phys Chem C Nanomater Interfaces. 2017; 121: 9191-9201.

107.Gao N, Zhang X, Liao S, Jia H, Wang Y. Polymer swelling induced conductive wrinkles for an ultrasensitive pressure sensor. ACS Macro Lett. 2016; 5: 823-827.

108. Melzer M, Lin G, Makarov D, Schmidt OG. Stretchable spin valves on elastomer membranes by predetermined periodic fracture and random wrinkling. Adv Mater. 2012; 24: 6468-6472.

109.Park J, Kim D-H, Levchenko A. Topotaxis: A new mechanism of directed cell migration in topographic ECM gradients. Biophys J. 2018; 114: 1257-1263.

110.Na S, Collin O, Chowdhury F, Tay B, Ouyang M, Wang Y, et al. Rapid signal transduction in living cells is a unique feature of mechanotransduction. Proc Natl Acad Sci USA. 2008; 105: 6626-6631. 
111.Wang N, Tytell JD, Ingber DE. Mechanotransduction at a distance: Mechanically coupling the extracellular matrix with the nucleus. Nat Rev Mol Cell Biol. 2009; 10: 75-82.

112.Park JY, Lee DH, Lee EJ, Lee SH. Study of cellular behaviors on concave and convex microstructures fabricated from elastic PDMS membranes. Lab Chip. 2009; 9: 2043-2049.

113.Pieuchot L, Marteau J, Guignandon A, Dos Santos T, Brigaud I, Chauvy P-F, et al. Curvotaxis directs cell migration through cell-scale curvature landscapes. Nat Commun. 2018; 9: 1-13.

114.Lee SJ, Yang S. Micro glass ball embedded gels to study cell mechanobiological responses to substrate curvatures. Rev Sci Instrum. 2012; 83: 094302.

115.He X, Jiang Y. Substrate curvature regulates cell migration. Phys Biol. 2017; 14: 035006.

116. Driscoll MK, Sun X, Guven C, Fourkas JT, Losert W. Cellular contact guidance through dynamic sensing of nanotopography. ACS Nano. 2014; 8: 3546-3555.

117. Uttayarat P, Toworfe GK, Dietrich F, Lelkes PI, Composto RJ. Topographic guidance of endothelial cells on silicone surfaces with micro-to nanogrooves: Orientation of actin filaments and focal adhesions. J Biomed Mater Res A. 2005; 75: 668-680.

118.Sun X, Driscoll MK, Guven C, Das S, Parent CA, Fourkas JT, et al. Asymmetric nanotopography biases cytoskeletal dynamics and promotes unidirectional cell guidance. Proc Natl Acad Sci. 2015; 112: 12557-12562.

119.Vassaux M, Pieuchot L, Anselme K, Bigerelle M, Milan JL. A biophysical model for curvatureguided cell migration. Biophys J. 2019; 117: 1136-1144.

120.Schwarz US, Erdmann T, Bischofs IB. Focal adhesions as mechanosensors: The two-spring model. Biosystems. 2006; 83: 225-232.

121.Vassaux M, Milan J. Stem cell mechanical behaviour modelling: Substrate's curvature influence during adhesion. Biomech Model Mechanobiol. 2017; 16: 1295-1308.

122.Werner M, Blanquer SB, Haimi SP, Korus G, Dunlop JW, Duda GN, et al. Surface curvature differentially regulates stem cell migration and differentiation via altered attachment morphology and nuclear deformation. Adv Sci. 2017; 4: 1600347.

123.Limbert G, Kuhl E. On skin microrelief and the emergence of expression micro-wrinkles. Soft Matter. 2018; 14: 1292-1300.

124.Sopher R, Gefen A. Effects of skin wrinkles, age and wetness on mechanical loads in the stratum corneum as related to skin lesions. Mater Sci Eng Comput. 2011; 49: 97-105.

125.Lévêque JL, Audoly B. Influence of Stratum Corneum on the entire skin mechanical properties, as predicted by a computational skin model. Skin Res Technol. 2013; 19: 42-46.

126. O'Brien ME, Chandra D, Wilson RC, Karoleski CM, Fuhrman CR, Leader JK, et al. Loss of skin elasticity is associated with pulmonary emphysema, biomarkers of inflammation, and matrix metalloproteinase activity in smokers. Respir Res 2019; 20: 128.

127.Phillips TJ, Symons J, Menon S, Group HS. Does hormone therapy improve age-related skin changes in postmenopausal women? A randomized, double-blind, double-dummy, placebocontrolled multicenter study assessing the effects of norethindrone acetate and ethinyl estradiol in the improvement of mild to moderate age-related skin changes in postmenopausal women. J Am Acad Dermatol. 2008; 59: 397-404.

128. Flynn C, McCormack BA. Finite element modelling of forearm skin wrinkling. Skin Res Technol. 2008; 14: 261-269.

129.Gago N, Pérez-López V, Sanz-Jaka JP, Cormenzana P, Eizaguirre I, Bernad A, et al. Agedependent depletion of human skin-derived progenitor cells. Stem Cells. 2009; 27: 1164-1172. 
130.Abaci HE, Gledhill K, Guo Z, Christiano AM, Shuler ML. Pumpless microfluidic platform for drug testing on human skin equivalents. Lab Chip. 2015; 15: 882-888.

131.Roger M, Fullard N, Costello L, Bradbury S, Markiewicz E, O'Reilly S, et al. Bioengineering the microanatomy of human skin. J Anat. 2019; 234: 438-455.

132.Vadillo-Rodríguez V, Guerra-García-Mora Al, Perera-Costa D, Gónzalez-Martín ML, FernándezCalderón MC. Bacterial response to spatially organized microtopographic surface patterns with nanometer scale roughness. Colloids Surf B Biointerfaces. 2018; 169: 340-347.

133.Teixeira P, Trindade A, Godinho M, Azeredo J, Oliveira R, Fonseca J. Staphylococcus epidermidis adhesion on modified urea/urethane elastomers. J Biomater Sci Polym Ed. 2006; 17: 239-246.

134.Epstein AK, Hong D, Kim P, Aizenberg J. Biofilm attachment reduction on bioinspired, dynamic, micro-wrinkling surfaces. New J Phys. 2013; 15: 095018.

135.Chen H, Liu Y, Slipchenko MN, Zhao X, Cheng JX, Kassab GS. The layered structure of coronary adventitia under mechanical load. Biophys J. 2011; 101: 2555-2562.

136.Štorgel N, Krajnc M, Mrak P, Štrus J, Ziherl P. Quantitative morphology of epithelial folds. Biophys J. 2016; 110: 269-277.

137. Fischer AH, Jacobson KA, Rose J, Zeller R. Hematoxylin and eosin staining of tissue and cell sections. CSH Protoc. 2008; 2008: pdb.prot4986.

138.Venteicher AS, Tirosh I, Hebert C, Yizhak K, Neftel C, Filbin MG, et al. Decoupling genetics, lineages, and microenvironment in IDH-mutant gliomas by single-cell RNA-seq. Science. 2017; 355: eaai8478.

139.Yen CF, Huang SJ, Lee CL, Wang HS, Liao SK. Molecular characteristics of the endometrium in uterine adenomyosis and its biochemical microenvironment. Reprod Sci. 2017; 24: 1346-1361.

140.Yang R, Amir J, Liu H, Chaqour B. Mechanical strain activates a program of genes functionally involved in paracrine signaling of angiogenesis. Physiol Genomics. 2008; 36: 1-14.

141.Paszek MJ, Zahir N, Johnson KR, Lakins JN, Rozenberg GI, Gefen A, et al. Tensional homeostasis and the malignant phenotype. Cancer Cell. 2005; 8: 241-254.

142. Chaudhuri O, Gu L, Klumpers D, Darnell M, Bencherif SA, Weaver JC, et al. Hydrogels with tunable stress relaxation regulate stem cell fate and activity. Nat Mater. 2016; 15: 326-334.

143. Blanchard GB, Kabla AJ, Schultz NL, Butler LC, Sanson B, Gorfinkiel N, et al. Tissue tectonics: Morphogenetic strain rates, cell shape change and intercalation. Nat Methods. 2009; 6: 458.

144.Agrawal A, Lee BH, Irvine SA, An J, Bhuthalingam R, Singh V, et al. Smooth muscle cell alignment and phenotype control by melt spun polycaprolactone fibers for seeding of tissue engineered blood vessels. Int J Biomater. 2015; 2015: 434876.

145.Uto K, Aoyagi T, DeForest CA, Hoffman AS, Ebara M. A combinational effect of "Bulk" and "Surface" shape-memory transitions on the regulation of cell alignment. Adv Healthc Mater. 2017; 6: 1601439.

146.Wang Z, Tonderys D, Leggett SE, Williams EK, Kiani MT, Steinberg RS, et al. Wrinkled, wavelength-tunable graphene-based surface topographies for directing cell alignment and morphology. Carbon. 2016; 97: 14-24.

147.Wang T, Luu TU, Chen A, Khine M, Liu WF. Topographical modulation of macrophage phenotype by shrink-film multi-scale wrinkles. Biomater Sci. 2016; 4: 948-952. 
148.Pocivavsek L, Ye SH, Pugar J, Tzeng E, Cerda E, Velankar S, et al. Active wrinkles to drive selfcleaning: A strategy for anti-thrombotic surfaces for vascular grafts. Biomaterials. 2019; 192: 226-234.

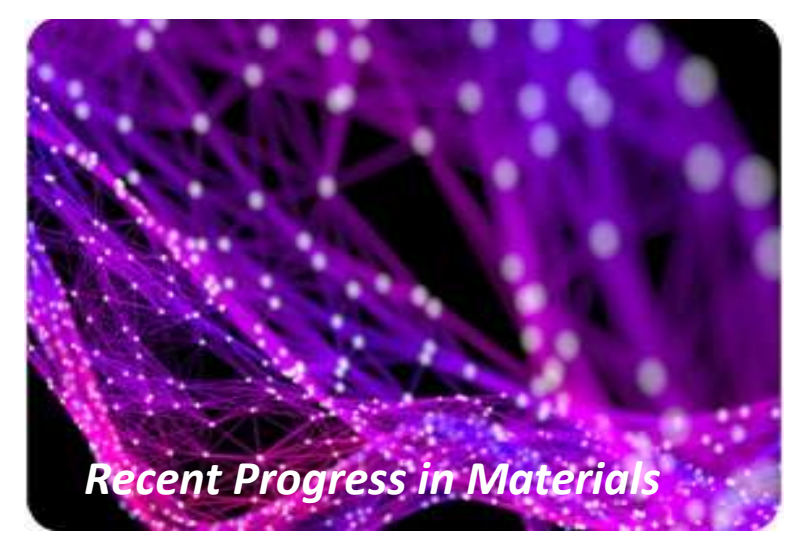

Progress in Materials by:

Enjoy Recent

1. Submitting a manuscript

2. Joining in volunteer reviewer bank

3. Joining Editorial Board

4. Guest editing a special issue

For more details, please visit:

http://www.lidsen.com/journals/rpm 